\title{
Nematic Liquid Crystal Composite Materials for DC and RF Switching
}

\author{
Mohiuddin Munna ${ }^{\circledR}$, Farhana Anwar and Ronald A. Coutu Jr. * \\ Department of Electrical and Computer Engineering, Marquette University, Milwaukee, WI 53233, USA; \\ mohiuddin.munna@marquette.edu (M.M.); farhana.anwar@marquette.edu (F.A.) \\ * Correspondence: ronald.coutu@marquette.edu; Tel.: +1-414-288-7316
}

Received: 11 February 2019; Accepted: 30 March 2019; Published: 2 April 2019

\begin{abstract}
Liquid Crystals (LCs) are widely used in display devices, electro-optic modulators, and optical switches. A field-induced electrical conductivity modulation in pure liquid crystals is very low which makes it less preferable for direct current (DC) and radio-frequency (RF) switching applications. According to the literature, a conductivity enhancement is possible by nanoparticle doping. Considering this aspect, we reviewed published works focused on an electric field-induced conductivity modulation in carbon nanotube-doped liquid crystal composites (LC-CNT composites). A two to four order of magnitude switching in electrical conductivity is observed by several groups. Both in-plane and out-of-plane device configurations are used. In plane configurations are preferable for micro-device fabrication. In this review article, we discussed published works reporting the elastic and molecular interaction of a carbon nanotube (CNT) with LC molecules, temperature and CNT concentration effects on electrical conductivity, local heating, and phase transition behavior during switching. Reversibility and switching speed are the two most important performance parameters of a switching device. It was found that dual frequency nematic liquid crystals (DFNLC) show a faster switching with a good reversibility, but the switching ratio is only two order of magnitudes. A better way to ensure reversibility with a large switching magnitude is to use two pairs of in-plane electrodes in a cross configuration. For completeness and comparison purposes, we briefly reviewed other nanoparticle- (i.e., Au and Ag) doped LC composite's conductivity behavior as well. Finally, based on the reported works reviewed in this article on field induced conductivity modulation, we proposed a novel idea of RF switching by LC composite materials. To support the idea, we simulated an LC composite-based RF device considering a simple analytical model. Our RF analysis suggests that a device made with an LC-CNT composite could show an acceptable performance. Several technological challenges needed to be addressed for a physical realization and are also discussed briefly.
\end{abstract}

Keywords: liquid crystal (LC); carbon nanotube (CNT); gold nanoparticle (GNP); electrical conductivity; direct current (DC); radio frequency (RF) switch

\section{Introduction}

A radio-frequency (RF) switch is a device that is used to route high-frequency signals (from hundreds of $\mathrm{MHz}$ to tens of $\mathrm{GHz}$ ) through a transmission line. RF switches are extensively used in wireless communication technologies (i.e., cellular and satellite communications). We need a material which shows a large and sharp change in resistivity in response to external stimuli to realize a high-performance RF switch. A low power consumption and a simple synthesis and fabrication process are also highly desired in the perspective of commercial applications. Taking this into account in this article, we reviewed published works reporting the conductivity modulation of carbon nanotube-doped liquid crystal (LC-CNT) composites and related aspects to reveal the possibility of 
the composites in DC and RF switching applications. Liquid crystals (LCs) are widely used in display technologies, photonic devices, electro-optic modulators, and optical switches for a long time [1-5]. For LC devices, the interaction between anisotropic dipole moments with external stimuli (temperature, electric fields, magnetic fields, and EM waves) is a major field of interest. LC shows orientational ordering which can be controlled by external stimuli, which modulates its properties. Furthermore, to modify LC's equilibrium properties (no external stimuli for perturbation), an LC matrix is often doped with nanoparticles (NPs) [6-8]. For example, a small concentration of $\mathrm{MgO}$ and $\mathrm{SiO}_{2}$ doping decreases the threshold voltage for field-induced reorientation $[9,10]$. Metal nanoparticles can alter the elastic coefficient and rotational viscosity of the composite [11,12]. Ferromagnetic and ferroelectric NP suspensions increase an LC's dielectric anisotropy [13]. Besides these NP doping, the incorporation of carbon nanotubes in liquid crystal is getting significant attention. Studies revealed that carbon nanotube (CNT) molecules can influence nematic ordering, which in turn alters the electrical properties of the LC matrix [14]. Moreover, an increase in LC alignments, an improvement in the electro-optic response for displays, a change in the nematic to isotropic transition temperature, and an alteration of the ion concentration are also observed in the LC-CNT composites [15-18]. The CNT doping effects are more noticeable for conductivity modulation than a dielectric constant modulation $[19,20]$. Figure 1 graphically summarizes the commonly used nanoparticles to enhance a liquid crystal's properties.

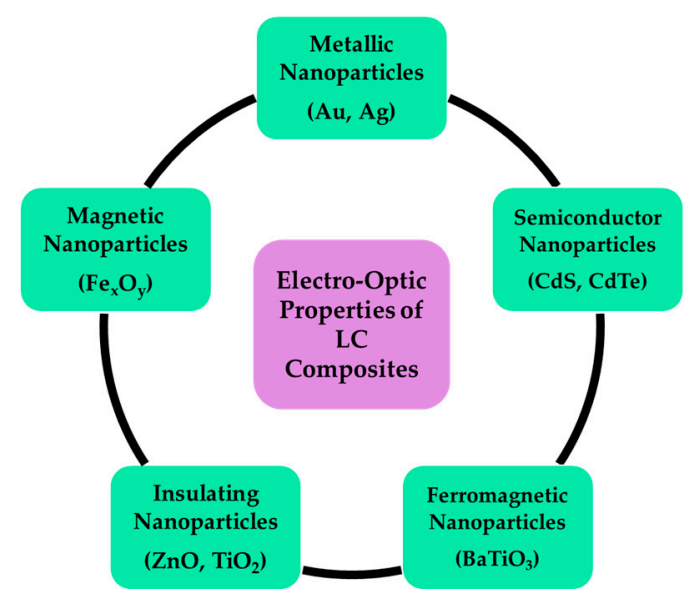

Figure 1. The types of nanoparticles commonly used as a dopant in liquid crystal matrices for altering electro-optical properties.

In this paper, we reviewed published work demonstrating the effects of CNT doping on LC-CNT composite's electrical behavior. We focused our discussion on field-induced conductivity modulation. After a brief discussion on liquid crystals and CNTs, we reviewed the effect of CNT on the composite's equilibrium (no applied field), electrical conductivity, and field-induced switching. Further, we reviewed the possible origin and physical mechanisms responsible for conductivity modulation. This may help researchers find a better way to further enhance conductivity modulation. We also reviewed a metal nanoparticle- (i.e., Au and Ag) doped LC composite's conductivity behavior to compare with LC-CNT composites. In Section 5, we compare different composite systems to point out which composite could be most suitable for DC and RF switching applications. Finally, we investigated composite material's RF switching capabilities with a simple analytical model to support the central idea of this review article. We did an RF simulation as a proof of concept. For the simulations, we used values reported on the literature and extrapolated the values for design optimization. We evaluated the transmission characteristics' loss up to $10 \mathrm{GHz}$.

\section{Electric-Field-Driven Conductivity Modulation in Pure Liquid Crystal Materials}

Liquid crystal is a state of matter having properties between solid crystal and conventional isotropic liquid. It can flow like liquids but still has a long-range orientation order and/or 
various degrees of translational/positional molecular ordering. Like crystals, LCs show anisotropic characteristics in dielectric constant, refractive index, and magnetic susceptibilities which vary with directions. In a nematic phase, where the LC molecules do not have any long-range transitional order, they show a preferred orientational order. For this ordering, a liquid crystal shows dielectric anisotropy $\left(\varepsilon_{\|}>\varepsilon_{\perp}\right)$ in a nematic phase. Both the parallel $\left(\varepsilon_{\|}\right)$and perpendicular $\left(\varepsilon_{\perp}\right)$ components of dielectric constant have strong dependences on temperature and frequency [21,22]. The typical behavior of a dielectric constant as the function of temperature and applied electric field frequencies is shown in Figure 2. An external perturbation can alter the macroscopic properties of the LC system. By applying mechanical, electrical, magnetic force, surface tension, or optical fields, we can rotate or modify the orientation order of the liquid. This, in turn, alters the LC sample properties [21,22]. For example, liquid crystal molecules have an electrical dipole moment. When an electric or magnetic field is applied, the dipole rotates and aligns the director (denoted by $\mathrm{n}$ ) along the field.

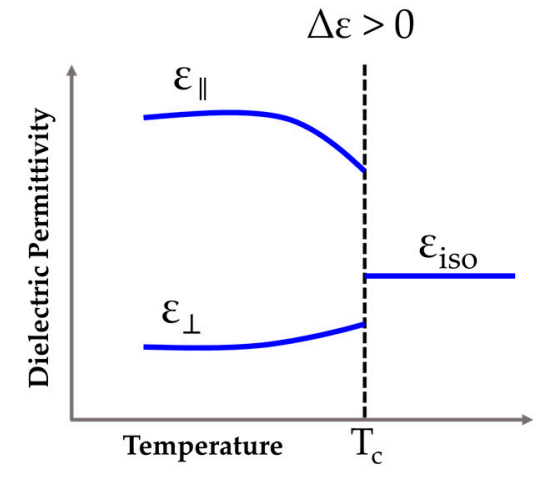

(a)

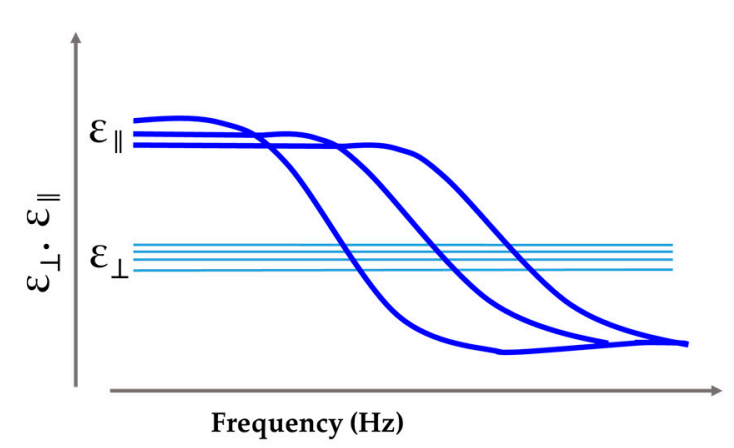

(b)

Figure 2. The typical anisotropic behavior of a liquid crystal: (a) The temperature dependence of dielectric anisotropy in liquid crystals and (b) the frequency dependence of the dielectric constants.

Pure liquid crystals (LC) are dielectric materials, and therefore, an LC cell filled with pure liquid crystal acts like capacitors. Therefore, when an electric field is applied to this cell, there is only a displacement current but no conduction current. Considering this, the electrical conductance and capacitance of liquid crystal cells can be modeled for high-voltage and low-voltage regions using Equation (1) [23]

$$
C=\omega C_{o} \varepsilon_{\gamma}^{\prime} G=\omega C_{o} \varepsilon_{\gamma}^{\prime \prime} \gamma=\left\{\begin{array}{l}
\perp \text { for } \mathrm{V}<\mathrm{V}_{\text {th }} \\
\| \text { for } \mathrm{V} \gg \mathrm{V}_{\text {th }}
\end{array}\right.
$$

where $C_{o}=\varepsilon_{0} A / d$ is called the geometric capacitance, $A$ is the electrode area, $d$ is the distance between the electrode, $\mathrm{V}_{\text {th }}$ is the threshold voltage of switching, and $\varepsilon^{\prime}$ and $\varepsilon^{\prime \prime}$ are the real and the imaginary parts of the dielectric constant, respectively. Overall, the dielectric constant of a liquid crystal is given as

$$
E=\varepsilon_{\perp} \cos ^{2} \theta+\varepsilon_{\|} \sin ^{2} \theta
$$

For voltages $<<\mathrm{V}_{\text {th }}$, the dielectric constant of the cell is equal to $\varepsilon_{\perp}$ as the $\mathrm{LC}$ director $(\mathrm{n})$ is aligned parallel to the electrodes. On the other hand, for voltages $>>V_{t h}$, the dielectric constant of the cell is equal to $\varepsilon_{\|}$as " $n$ " is aligned parallel to the direction of electric field. In pure liquid crystal materials, there is no free charge carrier or conductive path between electrodes. Therefore, the conductivity modulation from external stimuli (i.e., temperature, magnetic field, and electric field) is very low. Guralnik et al. showed that the capacitance and conductance of pure LC materials is a function of the magnitudes and frequencies of applied voltage and field induced modulation is only a few times [23]. The authors examined three commercial LC materials: LC1348, LC 1001, and E49 with the cell area in a $\mathrm{cm}^{2}$ scale and the cell separation in a micron scale. For all these materials, the capacitance values were in the $\mathrm{nF}$ range and LC1001 showed the lowest frequency dispersion. On the other hand, conductance 
varied on the scale of $\mu \mathrm{S}$. All three materials show frequency dispersion; the resistance decreases monotonically with frequency. For nondispersive $\mathrm{LC} 1348$ and $\mathrm{E} 49$, the quality factor $(\mathrm{Q}=\omega \mathrm{C} / \mathrm{G})>>1$. However, $\mathrm{Q}<<1$ for the dispersive dual frequency LC1001. Figure 3 shows an AC voltage-dependent electrical conductance and capacitance of a typical liquid crystal cell filled with E49 material. Here, the conductance increases more rapidly than capacitance with frequencies [23].

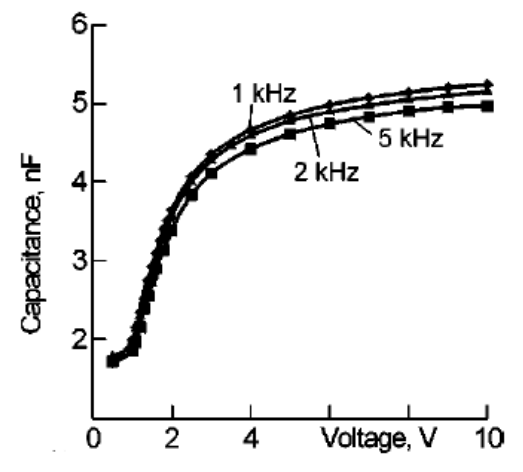

(a)

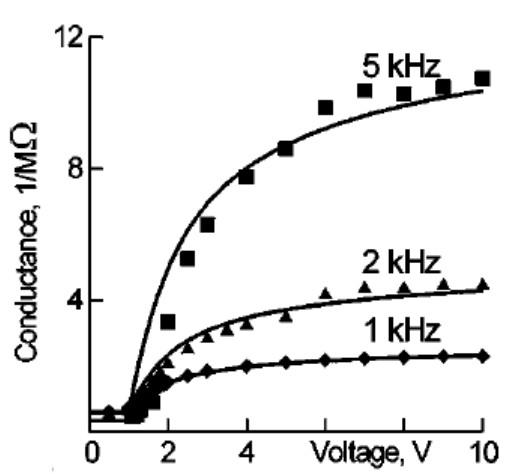

(b)

Figure 3. The cell capacitance and conductance for pure Liquid Crystal (LC) materials as function of the magnitude and frequency of applied voltage; (a) Capacitance modulation; (b) Conductance modulation [23].

\section{Electrical Conductivity of Liquid Crystal and Carbon Nanotube Composites}

\subsection{Review on Condutivity Behavior of LC-CNT Dispersions}

As discussed above, a field-induced conductivity modulation is very low for pure LCs. This makes traditional LCs less preferable for DC and RF switching applications. One possible solution to increase the ON/OFF resistivity ratio is to add nanoparticle dopants. When liquid crystal molecules orient themselves in an electric field, they can also orient guest atoms along with them through an elastic interaction. George H. Heilmeier et al. demonstrated that dye molecules can be aligned parallel to the electric field by LC molecules. For an LC cell of $12 \mu \mathrm{m}$ thickness, switching occurs within 1-5 ms for an electric field of $4 \times 10^{4} \mathrm{~V} / \mathrm{cm}$. After removing the electric field, the sample reverts to its initial condition in approximately $100 \mathrm{~ms}$. [24]. There are several works reported on enhancement field-induced conductivity modulations using nanoparticles $[6-10,19,20]$ Among all the nanoparticles, CNT might be the most suitable candidate for DC and RF switching as it is column is structured with a high aspect ratio and it has anisotropy in electrical conductivity. A small weight percentage of CNT does not change the composite's equilibrium (no external stimuli) conductivity much. Upon applying an electric field, various groups found a $2-4$ order of magnitude change in the electrical conductivity $[19,20]$. Although our main focus is on an LC-CNT composite, we discussed the electric-field-induced conductivity modulation in a metal-nanoparticle and an LC composite in Section 4 for comparison purposes as well.

Carbon nanotubes received enormous attention over the last three decades due to their unique electrical, mechanical, and optical properties [25-34]. CNTs are capable of altering LC matrix chemistry, viscosity, dispersion quality, etc. In addition to that, CNT can also modify the physical properties of the composites [35]. For example, a faster electro-optic response, an altered dielectric anisotropy, and a local deformation in the nematic director are observed [36-38]. The electrical conductivity of the material system can be modified by external stimuli like surface interaction and electrical, magnetic, optical, and thermal excitations. In all the cases, external stimuli do not have a direct interaction with the CNTs. LC molecules respond to the stimuli, which in turn interact with CNTs by elastic force and molecular interactions.

Studies revealed that the electrical conductivity of a LC-CNT mixture depends on the operational temperature, phase of LC, and CNT dopants concentration. Lebovka et al. showed that the conductivity 
behavior of p-ethoxy-benzylidene-p-n-butylaniline (EBBA)/Multiwalled Carbon Nanotube (MWCNT) composites is a function of CNT wt.\% (Figure 4) [39,40]. When the concertation exceeds a threshold concentration, which is also known as percolation threshold (which is $0.05-0.1 \%$ in the present case), the conductivity increased by several orders of magnitude. This is called percolation transition. A continuous conduction path is created by CNT clusters in the LC matrix. The ultrasmall critical concentration $(<0.1 \%)$ for insulation is due to the high aspect ratio of MWCNTs $(100-1000)$. A similar behavior is also observed for a $5 \mathrm{CB} / \mathrm{MWCNT}$ mixer with a similar critical concentration $\mathrm{C}=0.025 \mathrm{wt} . \%[40,41]$.

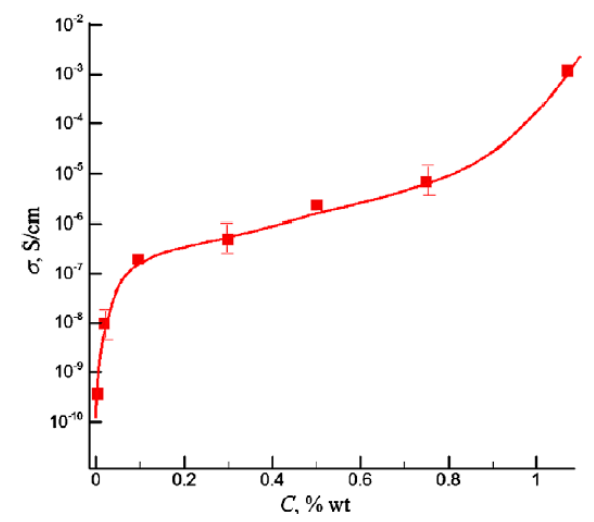

Figure 4. The electrical conductivity $(\sigma)$ of a carbon nanotube-doped liquid crystal (LC-CNT) composite versus the weight fraction (wt.\%) of carbon nanotubes (CNTs) [39].

Moreover, Lebovka et al. showed that an EBBA/MWCT conductivity shows a positive temperature coefficient and heating-cooling hysteresis behavior (Figure 5a). Above the crystalline-to-nematic phase transition temperature $\left(\mathrm{T}_{\mathrm{SN}}\right), \sigma$ increases with temperature. There is no discontinuity near the nematic to isotropic phase transition temperature, $\mathrm{T}_{\mathrm{NI}} \sim 351-353 \mathrm{~K}$. The hysteresis gap is the largest when a CNT doping concentration is close to the critical concertation of percolation transition as shown in Figure $5 b$.

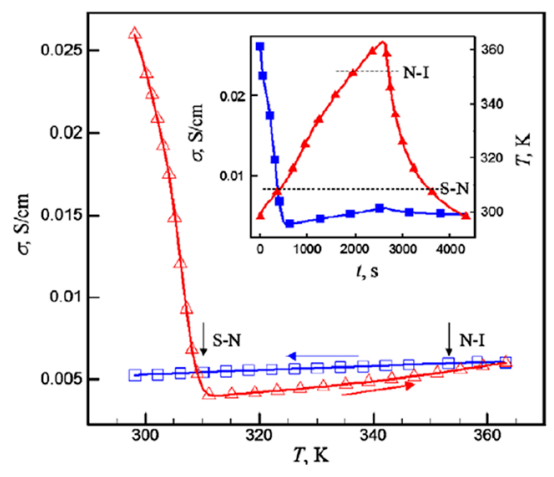

(a)

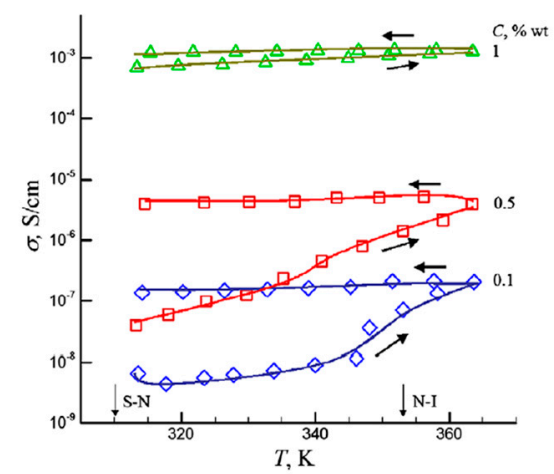

(b)

Figure 5. The electrical conductivity $(\sigma)$ versus temperature (here, $\mathrm{S}-\mathrm{N}=$ Solid-to-Nematic transition and N-I = Nematic-to-Isotropic transition); (a) $\mathrm{C}=1$ wt. $\%, \mathrm{f}=1 \mathrm{kHz}, \mathrm{U}=1 \mathrm{~V}$. The inset shows thet conductivity and temperature evolution with time $\mathbf{t}$; (b) The hysteresis behavior of an LC-CNT composite electrical conductivity in a heating-cooling cycle at different CNT doping concentrations [39].

It is evident that temperature strongly influences the spatial arrangement (orientation of the director) and percolation characteristics of LC composites. The optical transmission measurement of a LC-0.05 wt.\% CNT system done by Lisetski et al. is also in accord with this [41]. They reported that the CNT's contribution to the total absorption and scattering loss is a measure of the CNT's structural ordering. Although there is a 50\% loss in transmission after incorporating the CNT, the transiton in 
optical transmission-temperature characteristics indicates a strong effect of the temperature on the structural ordering of the system. In the nematic phase, CNTs orient themselves parallel to the LC director. On the other hand, the ordering of CNTs is insignificant for the isotropic phase.

According to Goncharuk et al., electrical conductivity shows a transient behavior at elevated temperatures for EBBA and MWCNT composites at a percolation threshold value of $0.1 \%$ [42]. Conductivity goes up over time with a dominant effect in the first hour after the sample is heated to the desired temperature. The increase in conductivity over time is a function of the incubation temperature. For example, if the sample is heated at $363 \mathrm{~K}$ (above $\mathrm{T}_{\mathrm{NI}}$ ), the electrical conductivity increases 15 times within $8 \mathrm{~h}$ of operation. This happens due the spatial aggregation of CNTs with time, and it is very prominent in the vicinity of percolation threshold [43].

\subsection{Field-Induced Reorientation of CNT in LC Matrices and Conductivity Modulation}

An intensive study has been done on orienting particles in ferronematic fluids [44]. A theoretical analysis using continuum fluid models predicts that it is possible to align anisometric particles in a bulk nematic crystal $[45,46]$. Polson et al. also did an accurate analysis for Single-Walled Carbon Nanotubes (SWCNTs) considering the molecular interaction [47]. Harte showed the evidence of CNT alignment in 5CB liquid crystal solution, but the degrees of order and CNT orientation have yet to be investigated [48]. Lynch et al. demonstrated the short- and long-range CNT ordering on a membrane surface [14]. They also showed that, in a 5CB nematic phase LC, CNTs were oriented parallel to the surface microgrooves with an orientational order of 0.7-0.9 (Figure 6). Furthermore, it was possible to control the alignment in the film by using an electric field. They deposited two copper pads separated by $20 \mu \mathrm{m}$ onto the membrane. By applying an in-plane electric field of about $1.8{\mathrm{~V} \mu \mathrm{m}^{-1}}^{-1}$ perpendicular to the grooves (along LC director), they found a significant reorientation of the LC director. With a sufficiently high coverage of SWCNT, a continuous conduction path formed between the two electrodes, resulting in a resistivity of $10^{1}-10^{2} \mathrm{~m} \Omega$ along the tube axis [48]. Dierking et al. demonstrated electrically driven OFF-ON and ON-OFF switches based on liquid crystal-nanotube dispersion [19]. They made an LC-CNT mixture by sonication and introduced it in a typical LC cell with a cell gap of $6 \mu \mathrm{m}$. They used two commercially available LC solutions: E7 and ZLI-2806 with positive and negative dielectric anisotropies respectively. The authors determined the orientation order of MWCNT (bundle length $20 \mu \mathrm{m}$ and width $3 \mu \mathrm{m}$ ) in E7 dispersion. It is evident that the MWCNT are aligned along the director of the $\mathrm{LC}$ with an order parameter $\mathrm{S}=0.9$. This is also reported by Lynch et al. for MWCNT in a 5CB solution with S = 0.7-0.9 [14]. Such an ordering happens for SWNT also but cannot be analyzed by optical microcopy because of their small size (on the order of $\mathrm{nm}$ ).

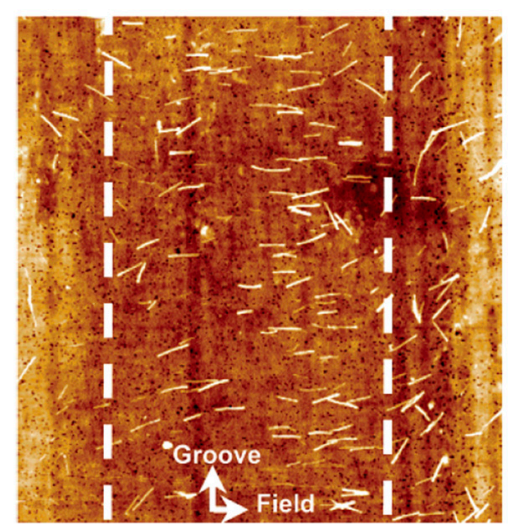

Figure 6. Controlling the orientation of a Multiwalled Carbon Nanotube (MWCNT) by an electric field: The two dashed lines are the copper electrodes to apply the electric field perpendicular to the surface microgrooves (for an initial alignment parallel to them). When the electric filed is above $1.8 \mathrm{~V} \mu \mathrm{m}^{-1}$, the CNTs reorient along the field direction [14]. 
Furthermore, they reoriented the CNTs by applying an AC electric field of $2 \mathrm{KHz}$ to the sandwiched cell. The E7 cell goes from a planer to homeotropic orientation as the voltage exceeded the threshold value of Freedericksz transition as illustrated in Figure 7. This induced a large increase in conductance for the E7-SWCNT system compared to only slight increses for the pure LC system. This is also reported by V. Jayalakshmi et al. for the same composite system, when the applied voltage exceeded the transition value of $2.3 \mathrm{~V}$ and the conductance increased dramatically by approx. 4 orders of magnitude [20]. This provides evidence that a CNT follows the field $=$ induced reorientation of the LC director. CNTs have an anisotropic conductivity, i.e., highly conductive along the tube axis but insulating across the tube. In the reorientation process, CNT bundles create a loosely connected network between the electrodes, forming a conducting path along its axis. A similar voltage dependent behavior was also found for E7-MWCNT as reported by Dierking et al. in their previous work [15]. However, in this case, the change was much higher. A longer size of the MWCNT might be the reason behind this. The opposite situation occurred for ZLI-2806-CNT dispersion. Liquid crystals went from a high conducting state to a low conducting state. When an electric field was applied, the system transited from a homeotropic orientation to a planner orientation due to its negative dielectric anisotropy.

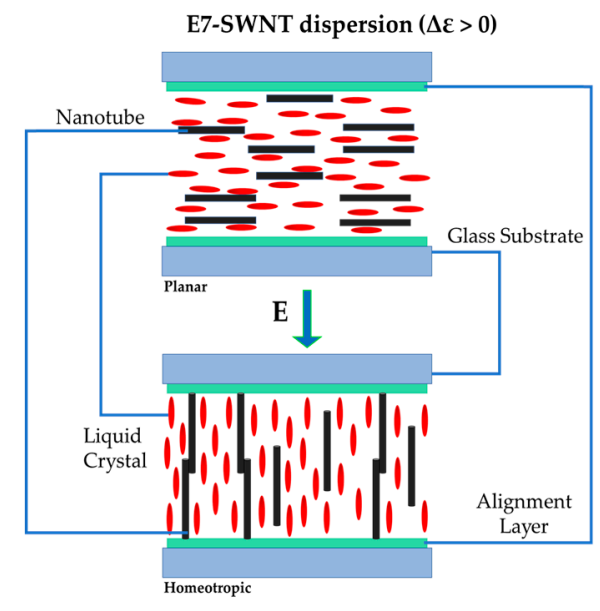

(a)

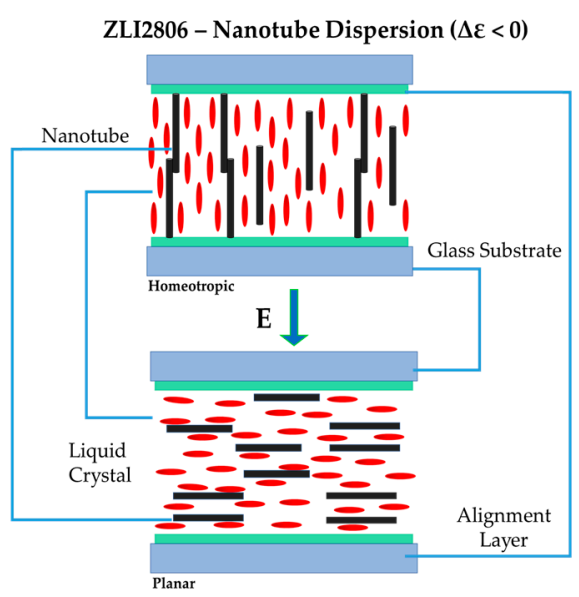

(b)

Figure 7. The electric-field-induced reorientation processes of CNTs in LC-CNT composites: (a) From a planar to homeotropic transition for a dielectrically positive LC-CNT dispersion and (b) from a homeotropic to planar transition for a dielectrically negative LC-CNT dispersion.

\subsection{Local Heating and Phase Transition during Switching}

Nanoparticles can significantly alter the nematic to isotropic phase transition behavior of liquid crystals. This phenomenon is very important in device applications as it impacts the LC composite properties, i.e., electrical, mechanical, etc. Metal-nanoparticle doping lowers the nematic to isotropic phase transition temperature $\left(\mathrm{T}_{\mathrm{NI}}\right)$ [49-51]. On the contrary, Hatice Duran et al. found that CNT doping can increase the $\mathrm{T}_{\mathrm{NI}}$. For this case, the transition temperature increased for E7 and the MWCNT mixture over a narrow range of nanotube concentrations for $0.1-0.2 \%$ (Figure 8) [52]. This is attributed to the anisotropic mutual alignment of LC molecules on MWCNT, stabilizing the nematic phase. They did the same experiment with fullerene to confirm that a high aspect ratio (anisotropic structure) of CNT can affect the phase stabilizaiton of the LC composite. Since fullerene is isotropic, there was no discernible change in $\mathrm{T}_{\mathrm{NI}}$. Such phase diagrams (Figure 8) help to select the suitable concentration of CNTs for different applications because the transition behavior will also affect the electrical conductivity chateristics of liquid crystal composites. 


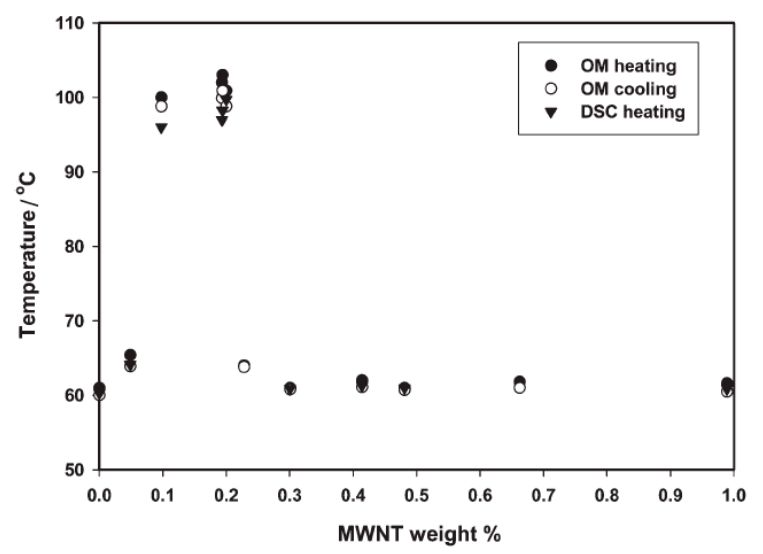

Figure 8. The nematic-isotropic transition temperature $\left(\mathrm{T}_{\mathrm{NI}}\right)$ versus weight percent of MWCNT: This phase diagram shows chimney type characteristics (OM = Optical Microscopy, DSC = Differential Scanning Calorimetry) [52].

Besides increases in $\mathrm{T}_{\mathrm{NI}}$, there are some other side effects of enhancing an LC composite's electric field-induced conductivity modulation by CNT doping. As field-induced conductivity increases by creating a high current path between electrodes, Joule heating will increase a local temperature which propagates to the entire cell with time. Shah et al. demonstrated an electric-field-controlled nematic to isotropic $(\mathrm{N}-\mathrm{I})$ phase transition in a $5 \mathrm{CB}\left(\mathrm{T}_{\mathrm{NI}}=42{ }^{\circ} \mathrm{C}\right.$, nematic range $\left.21-34.5^{\circ} \mathrm{C}\right)$ and annealed CNT mixture [53]. They filled an LC cell of an electrode separation of $5 \mu \mathrm{m}$ with an LC-CNT mixture without any alignment layer. At room temperature, they applied a $1 \mathrm{kHz}$ square wave with an amplitude $20 \mathrm{~V}_{\mathrm{pp}}$ on the cell. After a few tens of seconds, an isotropic domain started to form and eventually spread all over the cell within $100 \mathrm{~s}$ in a curtain-like fashion. Upon removal of the electric field, a nematic phase started to appear again after a few seconds. The entire cell came back to a nematic phase within $19 \mathrm{~s}$. Such an I-N transition is also overserved if the sample is heated externally. Most of the CNTs (5-60 $\mu \mathrm{m}$ of length) were longer than the cell height. Therefore, when the applied electric field is larger than Frederick's transition threshold, LC molecules rotated the CNTs. In this reorientation process, longer CNTs shortened the electrodes, making a high current path. This created local Joule heating around the CNTs. This, in turn, disturbed the nematic orders which propagate across the cell by a diffusion process. By the phase contrast mode of an optical microscope, they observed a field-induced isotropic bubble formation around the CNT bundles within a second. This indicates that faster switching is possible for nano- or microscale devices because an active switching volume is much lower compared to large devices (sized in $\mathrm{mm}$ range). Also, they observed a linear decrease in the switching time with an increasing CNT concentration in the range of $0.04 \mathrm{wt} . \%$ to $0.08 \mathrm{wt} . \%$. Below the threshold concentration, no complete transition occurs; only local isotropic droplets were formed. This observation confirmed that a low concentration of doping did not affect the LC property much. Other groups also found a similar observation. Baik et al. showed that minutes amount $\left(5 \times 10^{-4}\right.$ and $\left.10^{-3} \mathrm{wt} . \%\right)$ of CNT doping in a twisted nematic crystal cell do not perturb its orientational properties (cell capacitance, voltage holding ratio, etc.) in both the on and off states, but the residual DC field greatly reduced as CNTs trap ions [54]. To futher establish the idea that Joule heating is responsible for the transition, Shah et. al. performed the field-induced switching at elevated temperatures [53]. They found that switching is faster at a higher temperature, which is in agrement with their reasoning. Jayalakshmi et al. mentioned an additional source of local heating during field-induced switching [20]. They argued that applying an electric field to the LC-CNT composite may cause a dielectric breakdown after reaching a certain threshold value, which leads to local heating. Along with reorientation, this dielectric breakdown effect also increased the electrical conductivity of the composite. They found about an increase in conductivity, $\sigma$, by four orders of magnitude for the E7-0.05\% SWCNT system. However, the dielectric constant shows erratic behaviors above $5 \mathrm{~V}$ and even goes negative above $8 \mathrm{~V}$. In the Current-Voltage (I-V) measurement, a dramatic 
increase in the current is observed, which is indeed a characteristic of a dielectric breakdown [55]. Using a polarizing optical microscope, they observed an N-I transition (for the 8CB-CNT system) at $7.9 \mathrm{~V}$ and at a $36^{\circ} \mathrm{C}$ cell temperature [56]. Using an electric-field-induced heating model without considering the effect of CNT doping, they calculated the temperature increase of the composite that is enough $\left(10^{\circ} \mathrm{C}\right.$ increase at $\left.7 \mathrm{~V}\right)$ to derive the system into an isotropic phase. The peak length of the CNT used here is $500 \mathrm{~nm}$, which is much smaller than the cell gap at $70 \mu \mathrm{m}$. Therefore, a shortening of the cell electrode is not possible by a single nanotube as it happened for longer tubes [53]. Dierking et al. suggested that a loosely connected network CNT formed between the cell elctrodes, but this group argued that this alone cannot give such a large increase in conductivity $[15,19]$. Considering all these issues, they strongly claimed that a dielectric breakdown of the LC composite is largely responsible for the high conductivity change (not the inherent property of CNT). No other research group working on a similar LC-CNT composite has mentioned this aspect yet. A further investigation is required to explain the dielectric breakdown effect on conductivity. However, a dielectric breakdown and/or local heating is not desirable. If composites are subjected to these effects for a long time, chemical degradation may occur.

\subsection{Field Induced Conductivity Modulation in Isotropic Phase: $\pi-\pi$ Staking}

The conductivity modulation of a LC-CNT dispersion is also possible in the isotropic phase beside the nematic phase as described above. Basu et al. demonstrated an insulator to conductor transition in an MWCNTs/5CB composite in an isotropic phase [57]. In the nematic phase, LC molecules are subjected to a torque proportional to $\Delta \epsilon \mathrm{E}^{2}$ for an applied electric field, but in the isotropic phase, no interaction occurs as $\Delta \epsilon=0$. However, LC molecules of a specific moleculer structure can interact with CNTs. Giusy Scalia et al. observed a molecular interaction of 5CB with SWCNTs by Raman spectroscopy [58]. They suggested that the interaction occurs between the LC phenyl rings to the hexagonal structured CNT by $\pi$-staking. Using optical microscopy, they observed a stable nematic phase even above $\mathrm{T}_{\mathrm{NI}}$ around the CNT bundles in the 5CB-CNT dispersion. On the other hand, an isotropic phase is prevalent in the dispersion where CNT is absent. Furthermore, on the reverse process, an isotropic to nematic (I-N) transition nucleates at the CNT bundles in the cooling phase. These are clear evidences of a strong LC molecule interaction with CNTs. Using the Density Functional Theory (DFT), Kyung Ah Park et al. investigated the anchoring of an LC molecule on CNT [59]. The anchoring of LC molecules on CNT occurs by $\pi-\pi$ staking, maximizing the hexagon-hexagon interaction. A similar $\pi-\pi$ interaction is also observed for CNT and graphene composites [60,61]. The typical anchoring energy is $2 \mathrm{eV}$ [59], which is stronger than the Van der Waals force. This anchoring induces a short-range orientational order (both in the nematic and isotropic phases) of LC molecules around the CNT wall known as pseudo nematic domain (PND), as shown in the Figure 9. PND shows dielectric anisotropy $(\Delta \epsilon \neq 0)$ for an LC host matrix. Here, the LC molecules are oriented along the long tube axis. In the nematic phase, the effect of PNDs are overshadowed by the long-range order of LC itself. However, its effect is prominent in the isotropic phase $\left(\mathrm{T}=40^{\circ} \mathrm{C}\right.$ for $5 \mathrm{CB})$. Consequently, an electric field-induced orientation is possible in this case. PND can sustain in the isotropic phase even in a higher temperature as the thermal energy is not strong enough $(0.01 \mathrm{eV})$ to break the LC molecules anchoring.

Basu et al. investigated the field-induced resistivity modulation for pure 5CB, MWCNT in ethanol, and the 5CB/0.005 wt.\% MWCNT composite at a temperature greater than $\mathrm{T}_{\mathrm{NI}}$ (Figure 10) [57]. Pure 5CB and MWCNT in ethanol does not show any modulation, whereas a 5CB-CNT composite shows a drop in the resistivity of more than three orders of magnitude a threshold value of 7.26 V. In this case, randomly oriented PNDs align along the field, and several PND-capped CNTs made loosely connected conductive networks between the metal electrodes. 


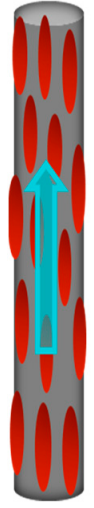

(a)

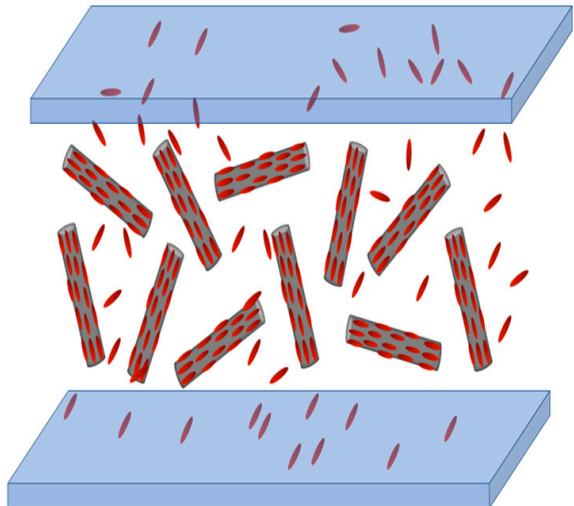

(b)

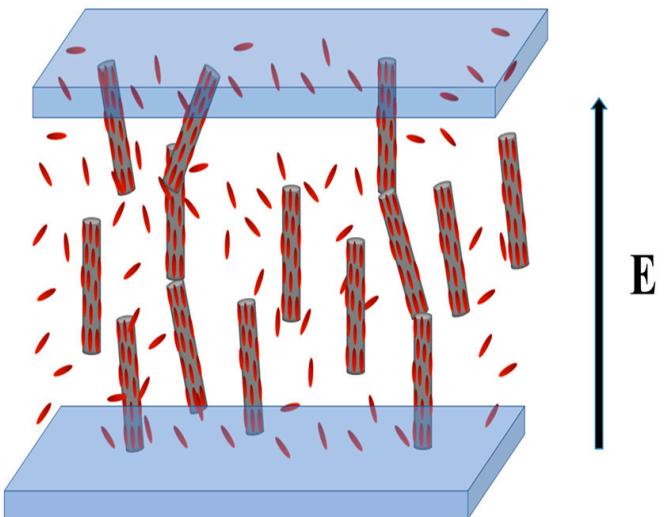

(c)

Figure 9. (a) Psudonematic domain (PND) formation around a CNT in an LC matrix; (b) PND in the isotropic phase; and (c) PND alignment along the electric field.

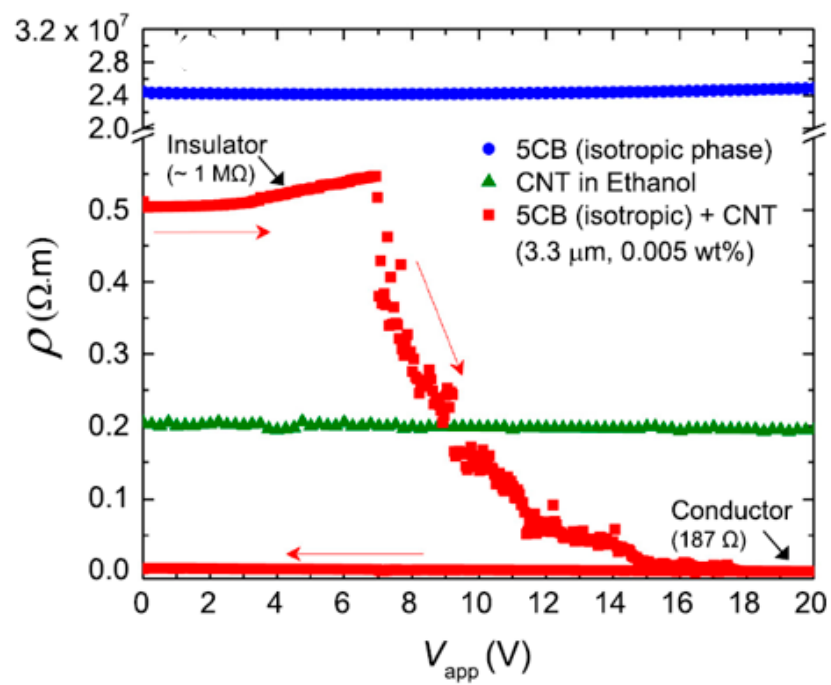

Figure 10. The field-induced resistivity modulation in $3.3 \mu \mathrm{m}$ cells for (i) pure 5CB in the isotropic phase at $\mathrm{T}=40{ }^{\circ} \mathrm{C}$ (the blue circle); (ii) CNT (0.005 wt. \%) in ethanol at room temperature (the green triangle), and (iii) $5 \mathrm{CB} / \mathrm{CNT}(0.005 \mathrm{wt} . \%)$ in the isotropic phase at $\mathrm{T}=40{ }^{\circ} \mathrm{C}$ (red square) [57].

The space between the cell electrode and CNT concentration has a strong influence on the conductive path (CNT wires) formation. Basu et al. observed that the threshold voltage $\left(\mathrm{V}_{\text {th }}\right)$ increases with cell separation. On the contrary, the threshold voltage was expected to decrease with CNT concentrations as the probability of forming a connected CNT network will increase [57]. However, in an experimental observation, they found an anomalous behavior. $V_{\text {th }}$ decreased for a CNT concentration ranging from 0.0018 to $0.005 \mathrm{wt} . \%$. After crossing this range, $\mathrm{V}_{\text {th }}$ started to increase since, above a critical concentration-in this case, it is $0.005 \mathrm{wt} . \%$ - CNT started to aggregate. It was also observed for other LC-CNT composites. Furthermore, in addition to the conductivity modulation, Joule heating was observed using a polarizing electron microscope as CNT wires made a high conducting path to draw huge amounts of currents. As there is no elastic interaction of CNTs with the LC medium in an isotropic phase, the insulator-to-conductor transition is irreversible. There is no restoring force to revert back the PNDs to break the CNT wire networks connecting the two electrodes of the LC cell. Basu et al. indeed observed no discernible change in resistivity even after one week of the insulator-to-conductor transition. This experiment verifies a nonvolatile electromechanical memory effect of the LC-CNT composites [57]. 
As mentioned earlier, PND formation can also occur in the case of a graphene/liquid crystal (LC-GP) composite $[60,61]$. Basu et al. demonstrated a field-induced conductivity modulation in the LC-GP composites [62]. They incorporate monolayer graphene flakes (average thickness of $0.35 \mathrm{~nm}$ and an average lateral size of $550 \mathrm{~nm}$ ) in MLC-1500-100, which shows an N-I transition at $101{ }^{\circ} \mathrm{C}$. The concentration of graphene ranges from $0.786 \times 10^{4}$ to $5.77 \times 10^{4} \mathrm{wt} . \%$. The incorporation of graphene (GP) stabilizes the nematic phase, and even in the isotropic phase, the composite shows dielectric anisotropy. It is well-known that graphene flakes act as a conductor in the in-plane directions, whereas it acts as insulator in the out-of-plane direction. The composite shows a significant increase in conductivity compared to pure LC upon the application of electric fields as shown in Figure 11. The possible explanation is the same as in the case of the CNT/5CB composite described above [57]. However, the increase in conductivity is only three times, which is much lower than the CNT/5CB composites.

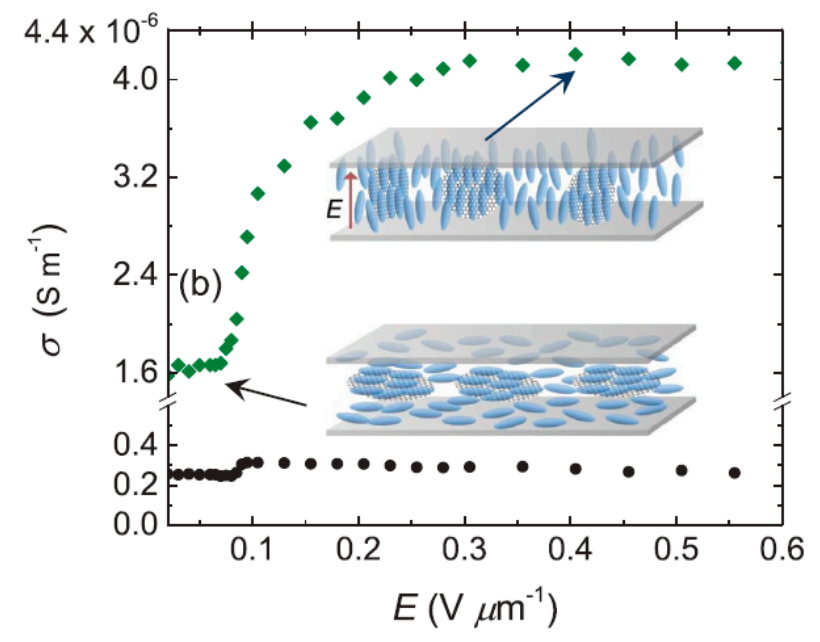

Figure 11. The electrical conductance, $\sigma$, as a function of the applied rms (root mean square) field $\mathrm{E}$ $(\mathrm{f}=1000 \mathrm{~Hz})$ in the nematic phase $\left(\mathrm{T}=50^{\circ} \mathrm{C}\right.$ ) for the pure LC and LC/graphene (GP) composite (GP concentration $2.29 \times 10^{4} \mathrm{wt}$. \%.) The reorientation of the graphene flakes with the nematic director is shown in the inset schematics [62].

One very important property for switching application is reversibility. In contrast to pure LC, an LC composite is known to show an irreversible electro-optic response. This phenomenon is called the electro-optic memory effect. The effect is characterized by an increasing optical transmittance with switching operation cycles. An electro-optic memory effect is observed in the LC-CNT composite by several groups $[57,59,63,64]$. Glushchnko et al. demonstrated irreversible memory effects on suspensions of aerosil particles in a 5CB liquid crystal [63]. They observed that the memory effect strongly depends on the LC media, filling concentration, and applied electric-field parameter (frequency and amplitude). Dolgov et al. showed that an EBBA/MWCNT composite shows a similar electro-optical response (Figure 12) [64]. When the CNT concentration is below $0.01 \mathrm{wt} . \%$, the response is reversible with a low conductivity. However, above $0.01 \mathrm{wt} . \%$, it starts to show irreversible effects and maximizes at $\mathrm{c}=0.02-0.05 \mathrm{wt} . \%$. Besides this, Basu et al. observed a memory effect in the 5CB-0.005 wt.\% MWCNT composite in the isotropic phase [65]. They found an irreversible change in the dielectric properties of the composite. They also explained the internal mechanism behind this effect by the formation of the pseudonematic domain as described above (Section 3.4). 


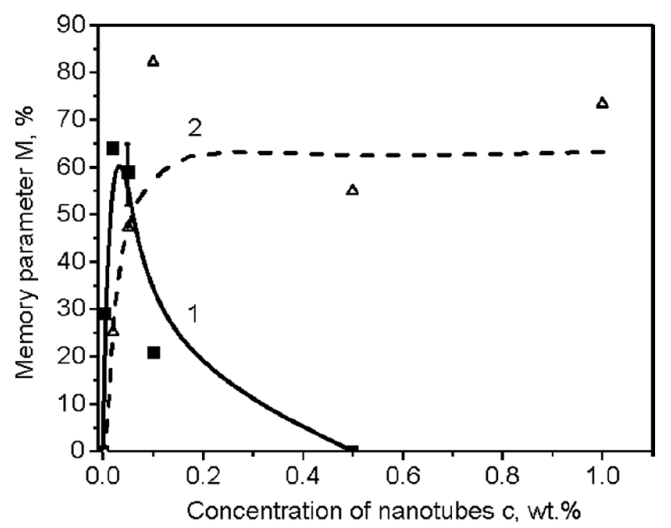

Figure 12. The memory efficiency $M$ as a function of the weight concentration of carbon nanotubes for the different liquid crystals mixtures: (1) p-ethoxy-benzylidene-p-n-butylaniline- (EBBA) based series and (2) MLC6608-based series [64].

\subsection{Field-Induced Conductivity Modulation in Isotropic Phase: In-Plane Switching}

Up to this point, we have discussed the effect of an out-of-plane applied electric field on an LC composite's electrical behavior. The in-plane field can also be used to modulate the LC composite property. The benefit of using an in-plane field is that it will ease the fabrication process and experimental testing setup. In 1992, an in-plane switching LCD was demonstrated by Kiefer et al. [66]. In the IPS (In-plane switching) mode of operation, two electrodes are placed on the same substrate in contrast to being put on the either side of the cell as in the vertical alignment mode or twisted nematic mode [67]. When a horizontal electric field is applied to an IPS cell, positive LC molecules rotate in plane to align themselves to the field directions. Figure 13 shows the field pattern for the IPS and FFS (fringe field switching) modes of in-plane swtitching. The threshold voltage of transition is inversely proportion to the cell gap [68]. Lee et al. showed that when the distance between electrodes is smaller than the width of the electrode and cell gap, the generated fringing field rotates the LC molecules above the bottom substrate [69]. By this way, electro-optical properties can be modified greatly. Sang Youn et al. investigated the CNT doping effect on the electro-optical properties of LC cells subjected to in-plane field [37]. They found a smaller retardation in the LC-CNT composite, resulting in a lower optical transmittance. In addition to that, they found a decrease in the decay response time compared to an undoped cell.
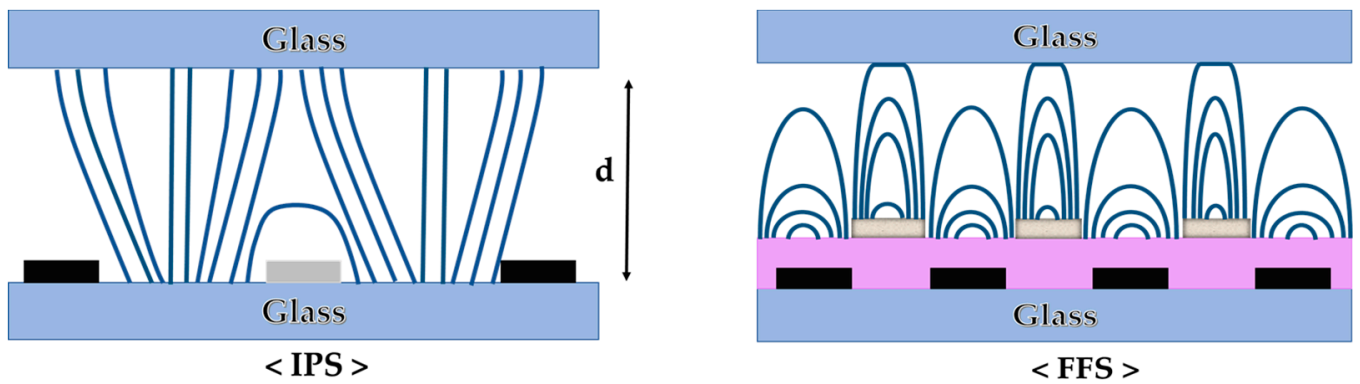

Figure 13. In-plane electrode configurations in an LC Cell: The black rectangle shows the metal electrodes, and the blue lines are equipotential lines generated by interdigital electrodes for in-plane switching (IPS) and fringe field switching (FFS) cells.

Volpati et al. investigated the electrical conductivity behavior of an LC-CNT composite by applying an in-plane electric field [70]. For the switching medium, they used E7 and 0.00005 to $0.01 \mathrm{wt} . \%$ SWCNT mixture. For testing, they fabricated gold electrodes as shown in Figure 14a. The measurement was done on an air ambient in contrast to a traditional sandwiched cell. They found the nonlinear Current-Voltage characteristic (I-V characteristic), which is a signature of field-induced 
conductivity modulation. In addition to that, they found an increase in conductivity on a subsequent sweep of the applied voltages. This indicates that the conductivity varies both with the operation time (how long the field is applied) and field strength. To verify the operational time dependence effect, they applied a fixed voltage of $7.5 \mathrm{~V}\left(1.5 \times 10^{5} \mathrm{~V} / \mathrm{m}\right)$ to the sample for a longer amount of time (say, for $30 \mathrm{~min}$ ) and they found an abrupt increase in the current in the first few minutes. Subsequently, upon the removal of the electric field, the current goes to zero immediately. Here, the conductivity modulation is occurred by CNT reorientation via nematic LC molecules [15], and the magnitude of saturation currents depended on the CNT concentrations. In all these experiments, the samples were subjected to an electric field on the order of $10^{5} \mathrm{~V} / \mathrm{m}$, which is enough to make a Fréedericksz transition, which is also observed by Dierking et al. for traditional cells [15]. Although CNT lengths are much smaller than the cell gap, multiple CNTs can bundle together to make a percolation path between electrodes. When the sample is exposed to a sufficient electric field for a longer time, the number of conduction paths increases by aligning the CNTs along the field.

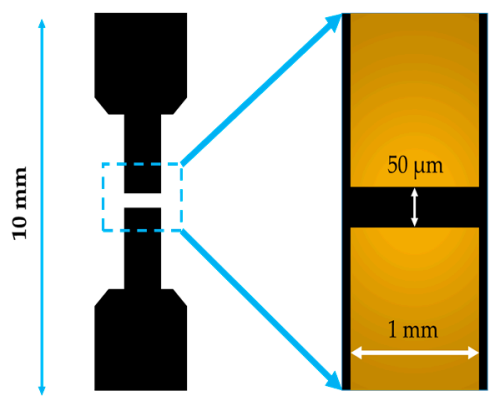

(a)

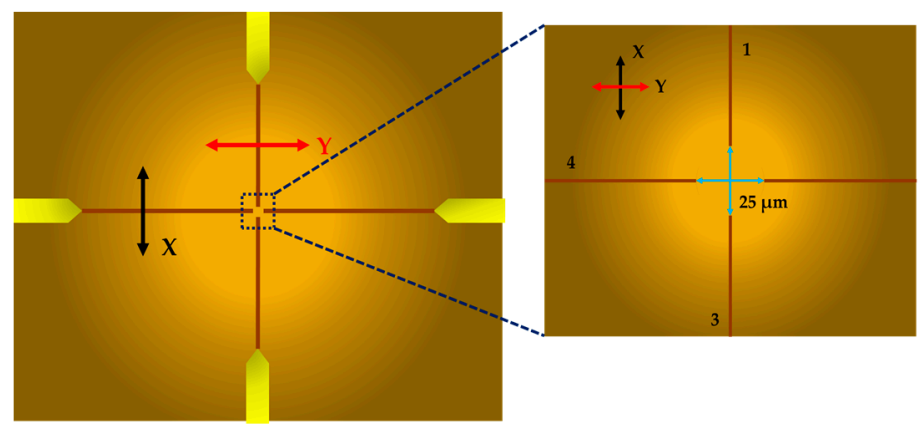

(b)

Figure 14. (a) In-plane gold electrodes having a 1-mm width and separated by $50 \mu \mathrm{m}$ in a glass wafer; (b) two pairs of electrodes in a cross configuration to inspect the conductivity in mutually perpendicular directions. The inset shows the gap in between the electrodes.

Polarizing microscopy shows that relatively small LC molecules can change orientation (relaxation) after the field is removed. To determine if reversible changes occur to CNTs as well, they did several I-V scans after the sample was exposed to the electric field of $10^{5} \mathrm{~V} / \mathrm{m}$ for $30 \mathrm{~min}$. The observation suggested that CNT has a tendency of permanent orientation. The possibility of controlling the composite's conductive pathways by applying an electric field from different directions was also investigated. This may facilitate a bistable reversible switching. Figure $14 \mathrm{~b}$ is a representation of this experimental arrangement. They fabricated two cross-plane electrodes so that they can apply an electric field in two mutually perpendicular directions in successive order. They applied a field of $4 \times 10^{5} \mathrm{~V} / \mathrm{m}(10 \mathrm{~V})$ in the $\mathrm{X}$ direction first and then in $\mathrm{Y}$ direction. The maximum current was $4 \mu \mathrm{A}$ for the $\mathrm{X}$-directed field, whereas it was $2 \mu \mathrm{A}$ in the $\mathrm{Y}$ direction. By reversing the directional order of electric field back and forth, they confirmed that the first measurement always gave a higher current value. Since fewer nanotube bundles align themselves in the new field directions, the current value in a second direction is comparatively lower. Therefore, many tubes aligned in the perpendicular to the second direction showed a tendency to retain their former orientation (irreversible tendency).

\subsection{Dual Frequency Switching}

Nematic liquid crystals (NLC) and their composites are widely used in various electro-optical devices. One of the main drawbacks of such devices is, they have long switching off time. It refers to the time required by the system to get back to its equilibrium state after turning off the field. When the field is taken away, the relaxation of the LC molecule is only driven by elastic torque. The elastic torque depends on the viscosity of the LC matrix, and it is a slow process, which makes the off time very long. Research are going on to cut down the switching off time. For example, Basu et al. doped NLCs with a small amount of CNT to achieve a faster field-induced switching [71]. Lee et al. and 
Liu et al. used SWCNT to improve the alignment layer to shorten the off time [72,73]. An alternative and effective way of faster switching is to use dual frequency nematic liquid crystals [74-76]. Dual frequency Nematic liquid crystals (DFNLCs, also abbreviated as DFLC) show a positive dielectric anisotropy at a lower frequency and a negative dielectric anisotropy at a high frequency. The frequency at which the sign changes is called the crossover frequency. For this frequency-driven reversible change in $\Delta \varepsilon$, it is possible to switch the LC director's orientation perpendicular or parallel to the applied field. This makes the switching very fast as the driving torque is very large (proportional to $\Delta \varepsilon$ ) compared to traditinal NLC. Dual frequency NLCs are applied in fast-operating phase modulators, optical shutters, tunable polarization filters, etc. [77-79]. On the other hand, some drawbacks of DFNLCs are the temperature dependence of a crossover frequency, the negative dielectric anisotropy is much bigger than that of positive one, etc. [80,81]. Another big concern is that, at high frequencies, power consumption is very high which also shifts the crossover frequency. Thus, it is desirable to operate the device in a moderate frequency range (for example, below $50 \mathrm{kHz}$ ) and to use those DFNLCs as the switching material, which have a low crossover frequency (i.e., $1 \mathrm{kHz}$ ) [82]. Usually DFNLCs are prepared by mixing two or more LC compounds from two categories of NLC. One category shows a positive $\Delta \varepsilon$ at a low frequency, which decreases as the operating frequency increases. Another category shows a negative $\Delta \varepsilon$ and shows very little frequency dependence up to the $\mathrm{MHz}$ frequency range. For the second category, a negative $\Delta \varepsilon$ is achieved by neighboring a fluoro substitution on the phenyl ring of LC molecules [83]. From the molecular point of view, positive LCs consist of large and long molecules with a longitudinal dipole moment $\left(\varepsilon_{\|}\right)$, whereas negative LCs consist of small molecules with a transverse dipole moment as shown in Figure 15a.

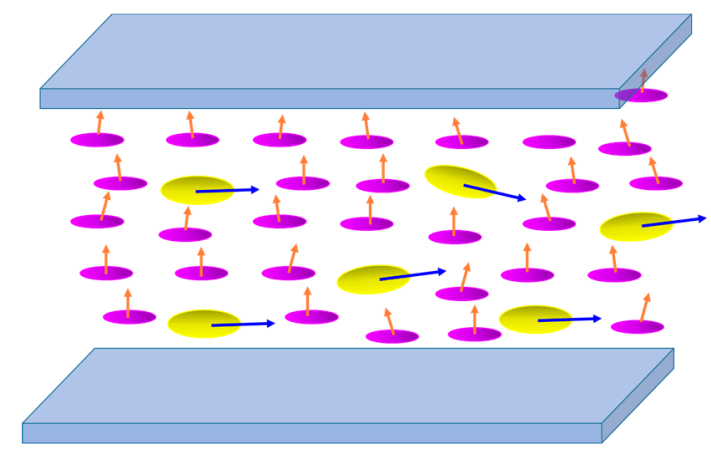

(a)

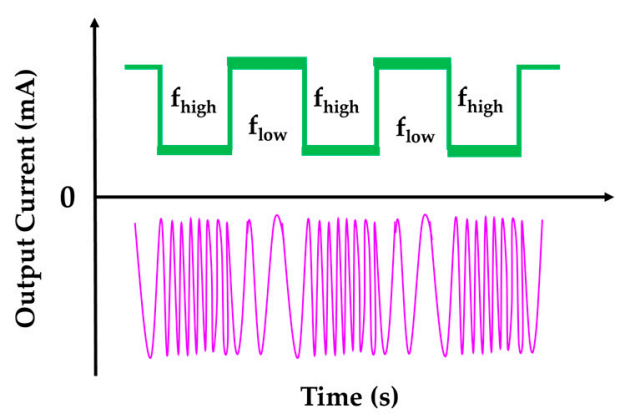

(b)

Figure 15. (a) A dual frequency nematic liquid crystals (DFNLC) mixture at the planar orientation: This mixture is composed of two categories of nematic liquid crystals (NLC), one having transverse (orange arrow) and other having longitudinal (blue arrow) dipole moments; (b) the bistable switching of a DFNLC/CNT composite with two applied frequencies for the ON state and the OFF state.

Prasad et al. demonstrated a frequency-driven conductivity switching in an LC-CNT composite. For their experiment, they used PCPBB (4-pentylphenyl 2-chloro-4-(4-pentylbenzoyloxy) benzoate) as a host material, which shows a nematic phase for the temperature range $0^{\circ} \mathrm{C}$ to $121.8^{\circ} \mathrm{C}$ [84]. They doped the host material with a $3.6 \times 10^{-4}$ volume fraction of SWCNT of peak length $500 \mathrm{~nm}$ and used a conventional ITO(Indium Tin oxide) -coated glass cell with a cell gap of 25-30 $\mu \mathrm{m}$ and an electrode sheet resistance of $10 \Omega$ /square. The equilibrium (no field applied) conductivity of LC's increased by two orders of magnitude upon doping with CNTs. Beside this, the conductivity became more temperature-dependent than the pure LCs. This comes from the fact that the activation energy of the PCCBB/CNT is low even for low doping concentration (about $0.05 \%$ ) compared to the MBBA/CNT system studied by Lebovka et al. [39]. In their experiment (Prasad et al.) the composite system was in a planer orientation initially [84]. For an applied electric field (above the Freedericksz threshold) and a frequency below the crossover frequency $\left(\mathrm{f}<<\mathrm{f}_{\mathrm{c}}\right)$, the system is in a positive dielectric state. The system experienced a torque of $\Delta \varepsilon \mathrm{E}^{2}$ which oriented the LC molecules along the field direction 
(i.e., perpendicular to the electrodes). As the $\sigma_{\|}$is high for an LC-CNT composite system, the system reached to a high conductivity state by loosely connected CNT networks. When the applied field frequency was above the crossover frequency $\left(f>f_{c}\right)$, the system was in a negative dielectric state and the LC molecules were oriented parallel to the electrodes. In this case, the system showed a low electrical conductivity. Here, a faster bistable switching was done with two applied frequencies: $500 \mathrm{~Hz}$ for the ON state and $600 \mathrm{kHz}$ for the OFF state (Figure 15b). Although, the LC molecules can be switched back to a planar orientation (parallel to the electrodes) by merely removing the electric field, this switching off process is quite slow as mentioned earlier. Using an alternating high- and low-frequency field, a faster switching can be achieved. In the present case, switching took place in milliseconds with on-off current ratio at 170 for an applied voltage of $10 \mathrm{~V}$ at an ambient temperature of $42{ }^{\circ} \mathrm{C}$ [84]. Further study on the DFNLC-CNT system is needed. The system can be optimized with other suitable hosts and by varying the concentration of CNT for attaining a higher ON-OFF ratio.

\section{Field-Induced Conductivity Enhancement in Metal Nanoparticle and Liquid Crystal Composite}

In this section, we review the effects of metal-nanoparticle (i.e., $\mathrm{Au}$ and $\mathrm{Ag}$ ) doping on the electrical conductivity behavior of LC matrices to compare with LC-CNT composites. Metal-nanoparticle doping has an impact on liquid crystal conductivity. The incorporation of Gold nanoparticles (GNPs) in a superstructure is an active field of research [85]. Works have been done to combine the self-assembly nature of liquid crystals and the excellent electrical/optical properties of gold nanoparticles to enhance the functionality of the composites. Some of these works are orientationally ordering gold nanorods [86], controlling light scattering electrically [87], field tuning plasmonic responses [88], light-driven molecular motor [89], etc. Doping a small number of GNPs in an LC matrix has a significant impact on its electrical conductivity. Prasad et al. observed nearly an increase of two orders of magnitude in the conductivity (both for $\sigma_{\perp}$ and $\sigma_{\|}$) by incorporating $5.0 \mathrm{wt} . \%$ alkanethiol-capped GNPs in a 5CB liquid crystal [49]. With temperature, both types of conductivity increase monotonically, except there is a small sudden decrease in $\sigma_{\|}$and a small sudden increase in $\sigma_{\perp}$ at $\mathrm{T}_{\mathrm{NI}}$ as shown in Figure 16. The conductivity anisotropy $\sigma_{\mathrm{a}}$ (i.e., $\sigma_{\|} / \sigma_{\perp}$ ) decreases with the GNP doping concentration and approaches 1 for higher concentrations. This indicates that the nematic behavior diminishes with the addition of GNPs. The possible explanation of this conductivity characteristics is, in liquid crystals, GNPs behave like ionic additive. It is evident by that fact that the activation energy is always lower for a composite compared to the pure compounds. Therefore, the incorporation of GNPs enhances the ionic jumps between atomic sites. The authors concluded that orientational ordering has only a little effect on this conductivity increase as they did not notice a drastic change in the conductivity during the N-I transition. However, they expect that the positionally ordered phase of LC (like the 1-D ordered smectic phase or the 3-D ordered B phase) may have an orientational ordering effect on conductivity.

Several works have been done to increase the conductivity of discotic liquid crystals by metal NP doping. Prasad et al. reported a moderate increase in conductivity by doping with $20-50 \mathrm{wt} . \%$ of GNPs $[90,91]$. In their later work, by doping with $1.0 \mathrm{wt} . \%$ of $2.4 \mathrm{~nm}$ GNPs coated with a triphenylene derivate in columnar discotic HAT7, they observed an increase of 6 orders of magnitude in the conductivity [92]. However, none of these works mentioned the effect of an electric field. Holt et al. demonstrated a field-induced increase in the conductivity of a discotic liquid crystal doped with only $1.0 \mathrm{wt} . \%$ of GNPs [93]. They use GNPs coated with a methylbenzene thiol dopant in HAT6 and Hexadecane liquid crystals. For HAT6 mixing, $1.0 \mathrm{wt} . \%$ of GNPs increased the conductivity by two orders of magnitude in all three phases (solid crystal, columnar liquid crystal, and isotropic liquid). Moreover, in the isotropic phase (above $100{ }^{\circ} \mathrm{C}$ ), applying an electric field above a certain threshold increases the conductivity another three to four orders of magnitude as shown in Figure 17a. However, this change is irreversible; conductivity does not change further even if you reduce, turn off, or even reverse the field, as shown in Figure $17 \mathrm{~b}$. Furthermore, in a cooling operation (from isotropic to LC phase to crystal phase), the high conductivity value is sustained. Similarly, in the 
case of a $1 \%$ GNP doping in hexadecane (Crystalline to isotropic phase transition temperature $18{ }^{\circ} \mathrm{C}$ ), similar orders of magnitude of an increase in conductivity was found, but the change disappeared (reversible) in the transition from the isotropic to crystalline phases (during cooling cycle). In both cases (HAT6/GNP and Hexadecane/GNP), conductive pathways are formed upon applying a sufficiently large electric field between the electrodes of LC cell, which is evident form the observation of the aggregation of nanoparticles in their interdigitated electrode experiments [93]. Here, the concentration of GNPs is well below the percolation limit, so the formation of conductive pathway is only possible by the field-induced organization of nanoparticles [94-96]. A possible explanation is GNPs moves in the electric field by electrophoresis, or an even field can also polarize the particles. This induces the self-assembly of particles (i.e., GNPs) by dipole-dipole interactions. This happened specially in the isotropic phase as LC shows a low viscosity, which eases the movement of GNPs. During crystallization. HAT6 can preserve the high conductivity, but the hexadecane composite cannot, as mention earlier. This is because, in the case of HAT6 during the cooling operation, homogeneously aligned grain boundaries are formed perpendicular to the electrodes, whereas in the case of hexadecane, grain boundaries are formed in a random orientation which disrupts the conductive GNP chains. Their major conclusion is that the orientational ordering of the LC molecules do not have much of an effect on the conductivity increase (specially in isotropic phase); the interaction between the gold nanoparticle and electric field plays the vital role [93]. Further investigations may be required to confirm this reasoning.

Although in an isotropic phase, LC molecules do not have any effect in the self-assembly of GNPs, a nanosphere can be organized by a liquid crystal matrix in the nematic phase. For example, Basu et. al demonstrated the self-assembly of CdS nanocrystals (quantum dots, QDs) in a 5CB liquid crystal matrix [97]. Even though Quantum dots (nanosphere) do not have anisotropy in electro-optic properties, their introduction may disrupt the uniform nematic alignment of the composite; thus, interns change its properties. It has been shown that the micrometer size spherical nanoparticle tends to be organized into a cylindrical chain directed to the global nematic director [98]. However, whether it is also applicable to a nanometer-sized particle was unknown. Basu et al. dispersed $1.0 \mathrm{wt} . \%$ of CdS nanocrystals (diameter of $2.3 \mathrm{~nm}$ ) in 5CB. By dielectric measurement, they found that the nanocrystal organized into a highly anisotropic structure along the LC director. The one-dimensional chain of QDs follows a global LC director orientation upon applying electric fields as shown in Figure 18. Moreover, there is no evidence of large-scale agglomerations of $\mathrm{QD}$ at any temperature.

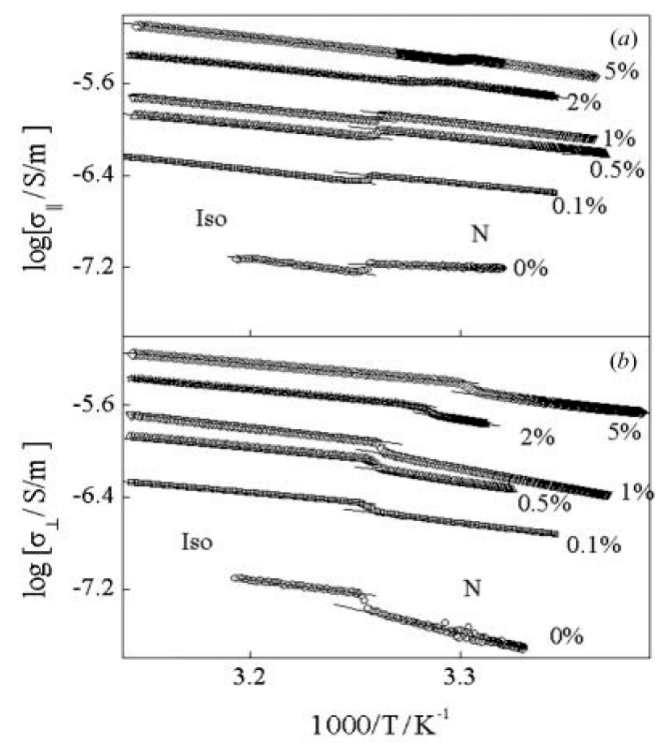

Figure 16. The temperature dependence of electrical conductivity in LC-CNT composites (in the nematic to isotropic phases) (a) along $\left(\sigma_{\|}\right)$and (b) perpendicular $\left(\sigma_{\perp}\right)$ to the director for the pure compound and LC-gold nanoparticle (GNP) composites with different doping concentrations [49]. 


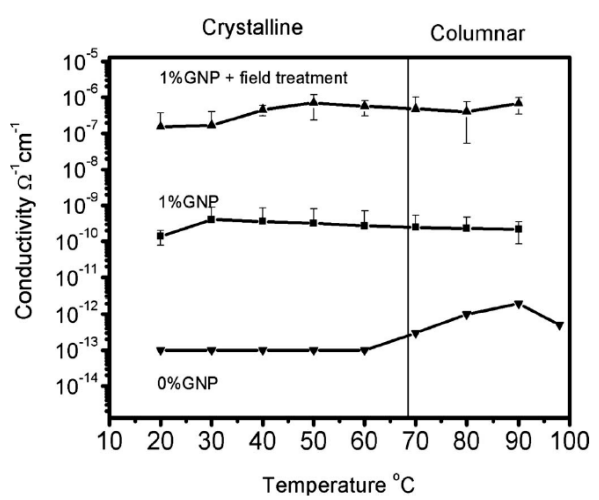

(a)

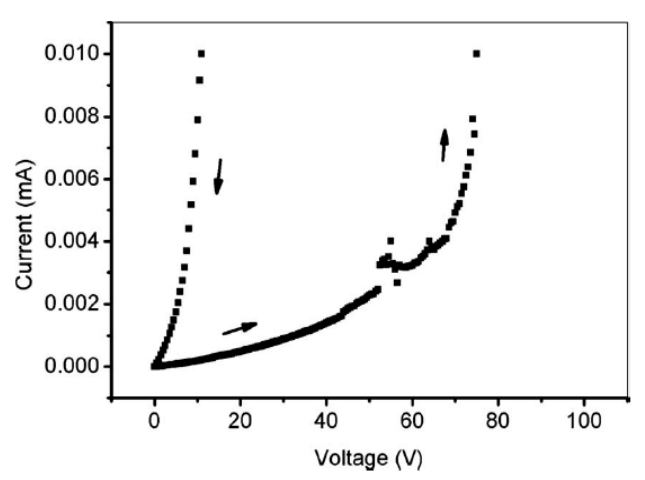

(b)

Figure 17. (a) The conductivity of a 1\% GNP in HAT6 as a function of temperature; (b) the I-V sweep of a thin film of $5 \%$ GNP in HAT6 in the isotropic phase at $105{ }^{\circ} \mathrm{C}$ [93].
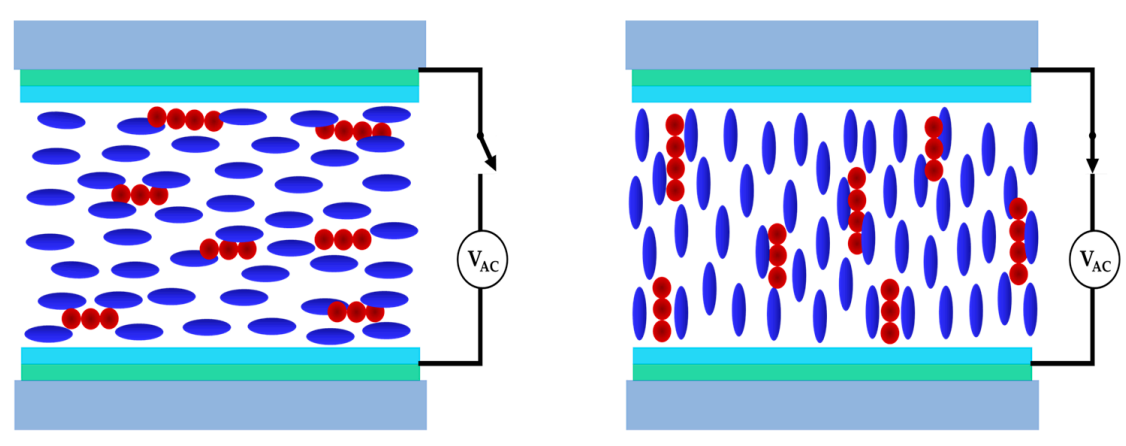

Glass

ITO Coating

Aligning Layer

Figure 18. The self-assembly and reorientation of quantum dots (QD) in a nematic LC matrix by electric field. (The LC molecules are colored blue, and the CdS QDs are sphere with purple color.)

The discussion above indicates the possibility of field-induced conductivity modulation in the nematic phase by incorporating metal nanoparticles in liquid crystal. Hadjichristov et al. demonstrated field-induced conductivity modulation in a silver NP-doped liquid crystal composite [99]. They doped a $5 \mathrm{CB}$ crystal with $0.5 \mathrm{wt} . \%$ of $\mathrm{Ag}$ nanosphere with a mean diameter of $10 \mathrm{~nm}$. The equilibrium conductivity (no applied electric field or other stimuli) of the composite enhanced after the incorporation of nanoparticles was also found of GNPs [49,100], as metal nanoparticle acts as ionic additives. By applying an AC voltage in the range of $1-20 \mathrm{~V}$, they observed about an increase of two orders of magnitude in the conductivity at a lower frequency region. They also confirmed their observation by DC measurement. All the measurements are done under ambient temperature. Instead of spherical QDs, metal nanoroad can also be used to enhance the conductivity of liquid crystal. Sridevi et. al shows about two orders of magnitude of enhancement in the electrical conductivity by incorporating $2 \mathrm{wt}$.\% of AuNRs (Gold nanorods, also abbreviated as GNRs) in an 8CB liquid crystal [11]. Besides this increase, the conductivity anisotropy of the LC/AuNRs composite is also stabilized (in contrast to the GNP/LC composite) [49]. An electric-field-driven mechanical rotation of the LC molecules can further enhance the LC/AuNRs composite conductivity, but the increase is insignificant (only $20 \%$ ). With a proper design and material selection, conductivity switching can be increased further for this system.

\section{Performance Comparison among Different Composite Systems}

In this section, we compared various composite systems reviewed in this article. It is difficult to make a comparison between various published works on field-induced conductivity modulation due to the lack of standardization. There are lots of parameters that can affect the conductivity behavior such as dimensions and types of nanoparticles, doping concentrations, cell or electrodes structures, 
frequency of applied field, operational temperature, purity liquid crystal host materials, etc. Different research group choose different combinations of these parameters in their experiments. Considering this difficulty, we tried to make a comparison among various reported works as summarized in Table 1 .

Table 1. A switching performance comparison among various composite systems.

\begin{tabular}{|c|c|c|c|c|c|}
\hline Composite & $\begin{array}{l}\text { Concentration } \\
\text { of NPs }\end{array}$ & $\begin{array}{c}\text { Operating } \\
\text { Temperature/Phase }\end{array}$ & $\begin{array}{l}\text { Resistivity } \\
\text { Ratio }\end{array}$ & $\begin{array}{c}\text { Mechanism of } \\
\text { Conductivity Modulation }\end{array}$ & Reference \\
\hline $\mathrm{E} 7 / \mathrm{CNT}$ & 0.05 wt. $\%$ & $\begin{array}{l}\text { Near RT, Nematic } \\
\text { phase }\end{array}$ & $10^{3}$ to $10^{4}$ & $\begin{array}{l}\text { Elastic interaction, } \\
\text { reorientation }\end{array}$ & $\begin{array}{l}\text { Jayalakshmi et } \\
\text { al. [20] }\end{array}$ \\
\hline $5 \mathrm{CB} / \mathrm{CNT}$ & 0.005 wt. $\%$ & $\begin{array}{c}40{ }^{\circ} \mathrm{C} \text {, Isotropic } \\
\text { phase }\end{array}$ & $5 \times 10^{3}$ & $\begin{array}{c}\pi-\pi \text { staking, PND } \\
\text { reorientation }\end{array}$ & Basu et al. [57] \\
\hline $\mathrm{PCPBB} / \mathrm{CNT}$ & $0.00036 \mathrm{vol} \%$ & $\begin{array}{c}42{ }^{\circ} \mathrm{C} \text { Nematic } \\
\text { phase }\end{array}$ & 170 & Dual frequency switching & $\begin{array}{c}\text { Prasad et al. } \\
\text { [84] }\end{array}$ \\
\hline HAT6/GNP & 1.0 wt. $\%$ & $\begin{array}{c}105^{\circ} \mathrm{C} \\
\text { Isotropic phase }\end{array}$ & $10^{3}$ to $10^{4}$ & Electrophoresis of GNPs & Holt et al. [93] \\
\hline $5 \mathrm{CB} / \mathrm{Ag} \mathrm{NPs}$ & 0.5 wt. $\%$ & Room temperature & $>10^{2}$ & $\begin{array}{l}\text { Self-assembly, } \\
\text { reorientation }\end{array}$ & $\begin{array}{l}\text { Hadjichristov } \\
\text { et al. [99] }\end{array}$ \\
\hline
\end{tabular}

As discussed in Section 3.1, the concentration of CNTs has a strong effect of the conductivity of LC composites. After a threshold concentration, the conductivity increases rapidly (Figure 4) [31]. However, we cannot increase the CNT concentration indefinitely, as the CNT aggregation (in a large bundle) rate increases with doping concentrations. Moreover, after a certain threshold, the CNT concentration also changes the phase transition behavior [44]. As shown in Figure 8, in the range of 0.1-0.2 wt.\% of CNTs, $\mathrm{T}_{\mathrm{NI}}$ increases significantly for an E7/MWCNT composite. A similar scenario is also expected for LC/SWCNT composites. Fortunately, in all the reported works in this article, the CNT doping concentrations are well below this critical range (Table 1). Although an LC/MWCNT composite shows a better field-induced conductivity modulation than LC/SWCNT as demonstrated by Dierking et al. for E7 host material [15], the problem with MWCNT is that they aggregate in large bundles as compared to SWCNT. If the length of the CNTs or CNT bundles are larger than the electrode spacing, then a single CNT can create a high current path. In this case, the conductivity might be very large but local heating is very prominent, which leads the system to an isotropic phase rapidly [53]. Local heating can also occur even if the CNT length is much smaller than the electrode spacing [20], but in this case, it may be less severe, as a loosely connected network has a higher resistance that a single CNT bundle. For the E7/CNT composite, the ON/OFF conductivity ratio is nearly four orders of magnitude, which is pretty good, but this cannot operate in the isotropic phase (in case local heating derives the system in the isotropic phase) [20]. For a 5CB/CNT composite, Basu et al. demonstrated a $5 \times 10^{3}$ order of magnitudes conductivity switching in an isotropic phase [57]. Although both of the systems had a comparable performance, the additional benefits of 5CB was that it had a room temperature nematic phase (in temperature range $21-34.5^{\circ} \mathrm{C}$ ) and it showed a field-induced switching both in the nematic and isotropic phases [53,57]. Dual frequency switching has an excellent performance in terms of switching speed, but the ON/OFF ratio demonstrated is only 170, which is much lower than that of the 5CB/CNT composite [84]. HAT6/GNP shows a similar $\mathrm{ON} / \mathrm{OFF}$ ratio to that of the $\mathrm{E} / \mathrm{CNT}$ composite, but the operational temperature $\left(105^{\circ} \mathrm{C}\right)$ is much higher than room temperature [93]. Moreover, this field-induced switching is completely irreversible. The 5CB/Ag NP composite shows two orders of magnitude switching at room temperature, but this is much lower than the LC/CNT composites reported here.

According to the discussion above, we found that the $5 \mathrm{CB} / \mathrm{CNT}$ composite is best-suited for a switching application. As $5 \mathrm{CB} / \mathrm{CNT}$ shows a near-room-temperature operation (both in the nematic and isotropic phases) with more than three orders of magnitude switching. For these reason, 5CB/CNT is a good candidate for switching application. We choose this material of our RF simulations. 


\section{Design and Simulation of LC-CNT-Based RF Devices}

Radio frequency switches are very important for an RF module in telecommunications and other technologies. Day by day. the demand for a high bit rate is increasing. Beside this, we need devices that can operate in a wide frequency range for multiband operations. 5G technology is on the way, so the demand of re-configurability is also increasing. For a good RF switch, we need a material which shows a large and sharp change in the resistivity for applied external stimuli (voltage, current, lights, etc.) like the phase change material, transitional metal oxide, etc. [101-105]. For a good RF device, a low ON resistance $(\Omega \mathrm{s})$, a low OFF capacitance $(\mathrm{fF})$, a low power consumption ( $\mu \mathrm{W}-\mathrm{mW}$ range), and a flat broad band response is required (up to $50 \mathrm{GHz}$ ).

In this work, we designed and simulated an LC composite-based SPST (Single pole single through)-RF as a proof of concept. The configuration for our device is a series-type coplanar waveguide (CPW). In this kind of device, the switching material is inserted in the middle of the signal line. Usually, when the device is in the OFF state, the switching material is in an insulating state and no signal will pass through. When the switching material switches to a conducting state, the signal can go through. In the present case, the switching material is the 5CB-CNT composite. Considering the fabrication process, we proposed two kinds of devices. In one fabrication process, at first, the gold line will be deposited using evaporation and the liftoff method (Figure 19). Then, these lines will be thickened to $10 \mu \mathrm{m}$ using electroplating. Finally, SU8 will be deposited in between the gold lines as a dielectric. In the second process, Deep reactive-ion etching (DRIE) can be used to make a trench on a $\mathrm{SiO}_{2} / \mathrm{Si}$ wafer (Figure 19). Then Au metal will be deposited to create the signal and ground lines.

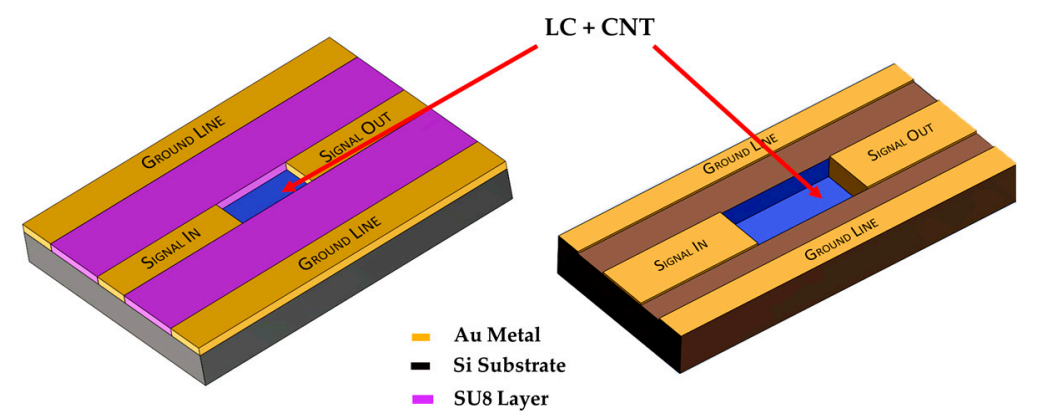

Figure 19. A schematic of two device structures of a coplanar waveguide (CPW) RF device.

For simulation, we proposed a simple model of the device ignoring the parasitic. Here, the LC composite is modeled as a capacitor in parallel with a variable resistor as shown in Figure 20b. We also assumed that the capacitance does not vary much between the ON and OFF states. Basu et al. demonstrated that, for a 3.3- $\mu \mathrm{m}$-thick cell with an area of approximately $50 \mathrm{~mm}^{2}$, the OFF-state resistance is $1 \mathrm{M} \Omega$ and the $\mathrm{ON}$ state resistance is $187 \Omega$ [57]. By optimizing the geometry, doping concentration, and host material, the $\mathrm{ON}$-state resistance might be reduced to a few $\Omega$ s. The typical value of the OFF state dielectric constant is around 5-10, with a cell spacing of 2-20 $\mu \mathrm{m}$ and an area of $25-100 \mathrm{~mm}^{2}[20,57,106]$. Considering these values, we optimized the capacitance using the formula $C$ $=\frac{\varepsilon_{\mathcal{E}_{o}} A}{d}$. We found that, the OFF capacitance can be optimized to less than $0.05 \mathrm{pF}$ (Figure 20a). 


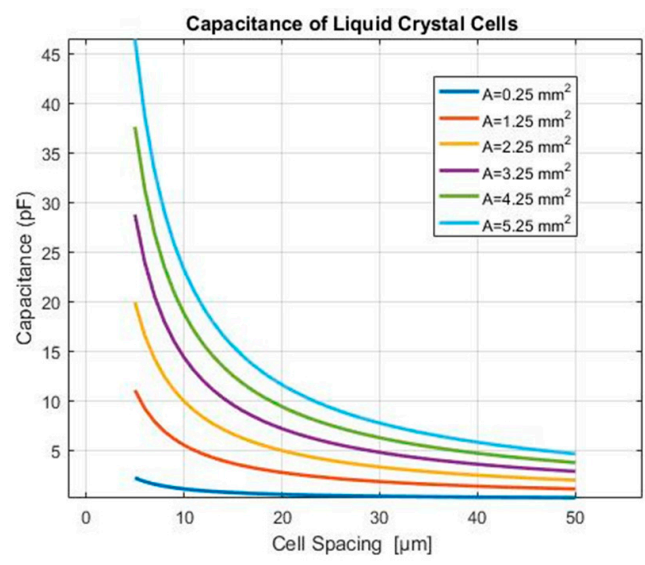

(a)

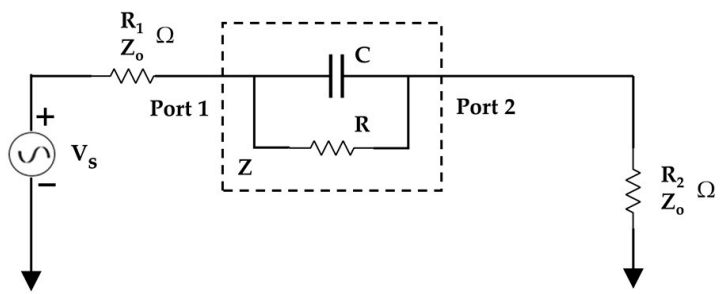

(b)

Figure 20. (a) Capacitance values as a function of cell distances and areas; (b) an LC composite-based RF device model ignoring the parasitic effects.

Using the above values of resistance and capacitance, we simulated the RF device using the NI-multisim software. Figures 21 and 22 show the RF performance of the proposed devices. Figure 21 shows transmission characteristics with two different pairs of resistance and capacitance values. In both cases, the insertion loss shows flat characteristics. The insertion loss for $R_{\text {on }}=5 \Omega$ and $C_{\text {off }}=0.05$ $\mathrm{pF}$ is $0.95 \mathrm{~dB}$ over a frequency range of up to $10 \mathrm{GHz}$, whereas the isolation is greater than $30 \mathrm{~dB}$ up to $10 \mathrm{GHz}$. On the other hand, the return loss for $\mathrm{R}_{\mathrm{on}}=50 \Omega$ and $\mathrm{C}_{\text {off }}=0.5 \mathrm{pF}$ shows a decreasing response with frequency. As the $R_{\text {on }}$ and $C_{\text {off }}$ values decreases, the response became flatter as shown in Figure 22b. For $R_{\text {on }}=5 \Omega$ and $C_{\text {off }}=0.05 \mathrm{pF}$, the return loss is $60 \mathrm{~dB}$ up to $10 \mathrm{GHz}$. This means that signal reflection is much less in the $\mathrm{ON}$ state.

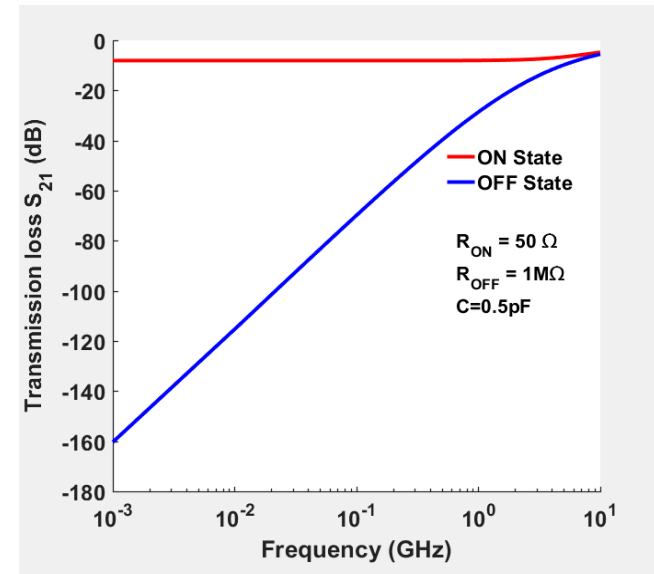

(a)

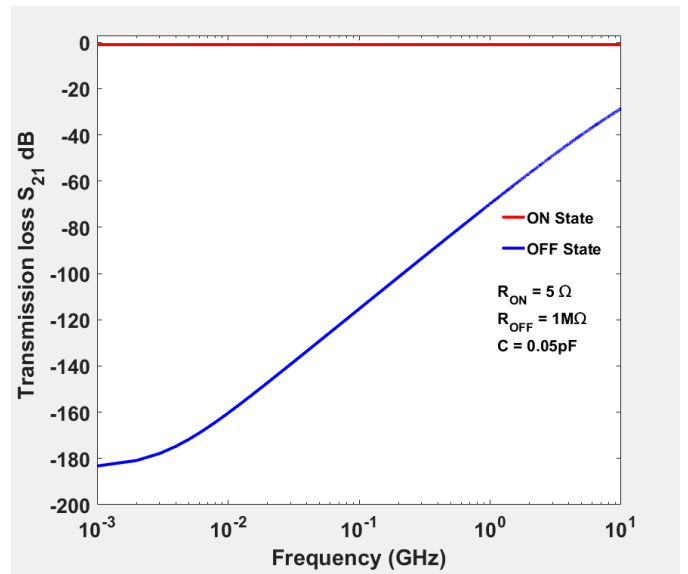

(b)

Figure 21. The transmission (insertion loss and isolation, denoted by $S_{21}$ ) characteristic of the proposed RF device; (a) For on state resistance, $R_{\text {on }}=50 \Omega$ and of state capacitance, $C_{\text {off }}=0.5 \mathrm{pF}$; (b) For on state resistance, $R_{\text {on }}=5 \Omega$ and of state capacitance, $C_{\text {off }}=0.05 \mathrm{pF}$. 


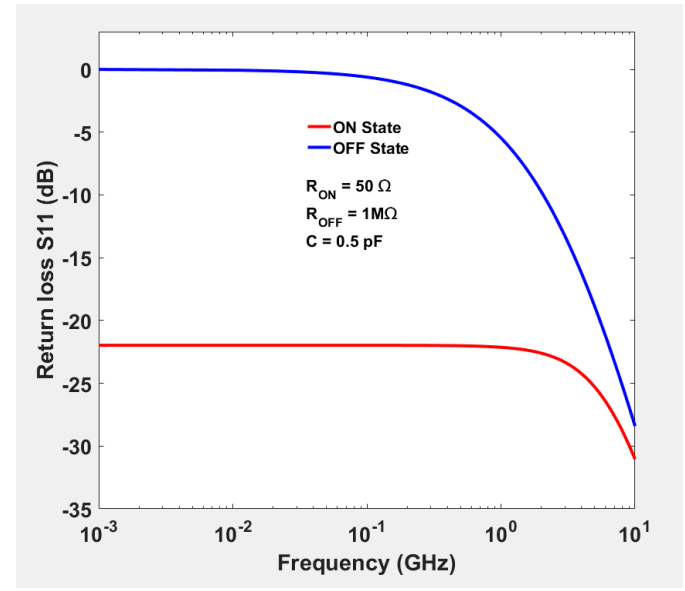

(a)

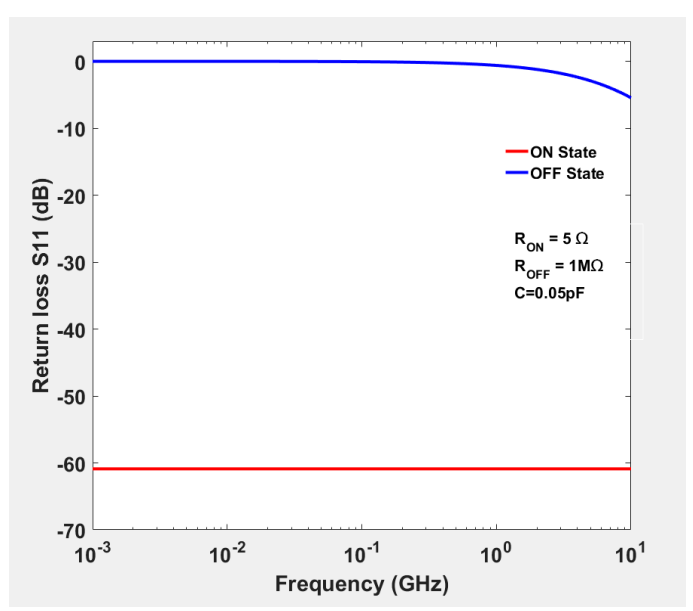

(b)

Figure 22. The transmission (return loss denoted by $\mathrm{S}_{11}$ ) characteristic of the proposed RF device. (a) For on state resistance, $R_{\text {on }}=50 \Omega$ and of state capacitance, $C_{\text {off }}=0.5 \mathrm{pF}$; $(\mathbf{b})$ For on state resistance, $\mathrm{R}_{\mathrm{on}}=5 \Omega$ and of state capacitance, $\mathrm{C}_{\mathrm{off}}=0.05 \mathrm{pF}$.

Table 2 summarizes the RF performance parameters of the device for different values of $R_{\text {on }}$ and $\mathrm{C}_{\text {off }}$. For acceptable transmission characteristics, $R_{\text {on }}$ should be less than $5 \Omega$ and $C_{\text {off }}$ should be less than $0.05 \mathrm{pF}$.

Table 2. The RF performance parameters of the device.

\begin{tabular}{ccccc}
\hline $\mathbf{R}_{\mathbf{O N}}(\boldsymbol{\Omega})$ & $\mathbf{C}_{\mathbf{O F F}}(\mathbf{p F})$ & $\begin{array}{c}\text { Insertion loss at 10 } \\
\mathbf{G H z}(\mathbf{d B})\end{array}$ & $\begin{array}{c}\text { Isolation at 10 } \\
\mathbf{G H z}(\mathbf{d B})\end{array}$ & $\begin{array}{c}\text { Return loss at 10 } \\
\mathbf{G H z}(\mathbf{d B})\end{array}$ \\
\hline 50 & 0.5 & 5.7 & 6 & 31 \\
20 & 0.5 & 3 & No data & 38.6 \\
5 & 0.5 & 0.96 & No data & 60.9 \\
5 & 0.05 & 0.95 & 30 & 61 \\
\hline
\end{tabular}

\section{Discussion}

In this paper, we reviewed the effect of NP doping (focusing on CNT doping) on an LC composite's electrical conductivity. We focused on electric-field-induced conductivity modulation, considering possible applications of the composite for DC and RF switching. We also described issues associated with field-induced conductivity modulation. Some of these issues need to be overcome to realize an efficient DC and RF switching device. After a brief discussion on liquid crystals, we discussed electric-field-driven conductivity modulation in pure liquid crystals. It is reported that the conductivity change of pure LC materials is very low, which is unacceptable in DC and RF switching application. To enhance the conductivity, one possible way is to dope the LC with a small amount of CNTs. At first, we reviewed the seminal work of Dierking et al. [15,19], which described how the field-induced reorientation of LC molecules modulate the conductivity of the LC-CNT composites through elastic interactions. Then, we discussed how the doping concentration and temperature alters the conductivity and switching behavior. There is a solubility limit for CNT doping in LC matrices. CNT tends to aggerate into large bundles in LC media as concentration increases. In addition to that, in a small window of CNT doping concentrations, the nematic to isotropic transition temperature $\left(\mathrm{T}_{\mathrm{NI}}\right)$ change a lot. During field-induced switching, Joule heating in the conductive state can drive the system to an isotropic phase from the nematic phase [20]. Besides in the nematic phase, conductivity modulation can also be achieved in the isotropic phase for some LC composites. In this case, LC molecules anchor on the CNT wall and form a pseudonematic domain; these PNDs interact with an external electric field. One of the major issues with switching is irreversibility, also described as memory effect. The memory 
effect increases upon doping with CNTs and other nanoparticles. Although out-of-plane devices are prominent, there are works on in-plane switching with a very simple microfabrication technique. An in-plane cross-electrode configuration could be a viable solution for reversible switching [70]. For device application, switching speed is a very important performance parameter. Most of the NLC devices suffer from a longer switching time. A faster switching is achievable through dual frequency nematic liquid crystal materials [84]. After the discussion of LC-CNTs' conductivity behavior, we also discussed field-controlled conductivity modulation in an LC/metal-nanoparticle composite to compare their performances with LC-CNT composites.

Finally, we proposed a simple model for an RF switching device using LC composite materials. With this simple analytical model, we simulated and analyzed some RF performance parameters. Although the application of LC composites in the field of RF switching fields are not explored yet, our simulation suggests that LC-based devices could open a new avenue. However, to make an efficient microswitch, some issues or challenges need to be considered, which are summarized below.

(a) Microfabrication and alignment: Most of the reported work on field-induced switching is done on conventional LC-sandwiched cells made of ITO-coated glass. These are macroscale devices and are easy to fabricate. According to our simulation results, to meet the RF switching requirement, devices need to be scaled down to microscale. However, in microscale, electrode deposition and making an alignment layer is a challenge. However, there are some works on the microfabrication of LC-based devices. For example, Garbovskiy et al. demonstrated an LC phase shifter using inverted microstrip line configuration [107]. Lai et al. described a fabrication technique for an in-plane LC-CNT-based device made of interdigitated electrodes for gas sensing application [108]. Varanytsia et al. used photolithography-patterned graphene electrodes instead of ITO for a better optical transmission characteristic of LC devices. Besides fabrication complexity in microscale, making alignment layers could be challenging. However, some groups demonstrated alignment LC in microscale. Varghese et al. described a micro-rubbing technique for LC alignment [109]. Nano-imprint lithography could be used for patterned alignments in microscale [110-112]. Photo-induced alignment is another option for patterned alignments in microscale. Along with these, a few other micro-patterning techniques are also reported [113,114].

(b) CNT has a tendency to aggregate in an LC solution. This is responsible for the poor CNT solubility in LC solutions. The dispersion quality degrades with time. A very common way to make a homogeneous dispersion is a magnetic string followed by sonication $[115,116]$.

(c) Reversible switching will be a challenge as LC-CNT composites show the memory effect. Considering this issue, DFNLC is a good option, but in this case, the switching ratio is only 170 as reported by Prasad et al [84]. An in-plane cross-electrode configuration [70] is a viable solution, but this will bring additional fabrication complexity. In addition to this, repeatable measurement behavior is also desired.

(d) In most of the reported works, an AC electric field is applied for switching to avoid ion migration during switching. For DC switching, the materials need to be ion-free.

(e) During conductivity switching, Joule heating may occur, which drives the system from a nematic to isotropic phase [20,53]. If the sample is subjected to heating for a long time, chemical degradation may occur. To prevent this, the system should be operated in constant current mode. Another way to prevent the phase changing is to keep the system in a constant temperature using a feedback system.

(f) To design an efficient switch, dynamical and transient behaviors need to be studied. However. there are few reports on the dynamical switching behavior. From the work of D. Volpati et al., it seems the switching can take place within a few seconds [70]. Shah et al. observed the field-induced isotropic bubble formation around the CNT bundles within a second [53]. Heilmeier et al. demonstrated that switching occurs within 1-5 ms [24]. 
According to the discussion above, we found that a $5 \mathrm{CB} / \mathrm{CNT}$ composite might be best-suited for switching applications. As $5 \mathrm{CB} / \mathrm{CNT}$ shows a near room-temperature operation (both in the nematic and isotropic phase) with more than three orders of magnitude switching. We chose this material for our RF simulations. We did an RF simulation as a proof of concept.

\section{Conclusions}

According to the reported works in this article, a small percent of NP doping changes the LC composite's intrinsic conductivity significantly. In addition to that, 2-4 orders of magnitude of electric field-induced conductivity switching is demonstrated by several groups. We reviewed the field-induced electrical switching behavior and related issues for LC-NP composites (focusing on LC-CNT composites) which are important in device perspectives. By comparing several technological aspects, we found that the $5 \mathrm{CB} / \mathrm{CNT}$ system could be a good choice in terms of DC and RF switching application. This composite shows more than three orders of magnitude switching near room temperature (both in the nematic and isotropic phase). The synthesis and processing of LC materials is well-established and, thus, makes it an attractive option for switching applications. In addition, optoelectronic devices and switches made from LC materials consume less power than comparable opto-mechanical technologies. Also, our simulations and analyses suggest that RF switching with an acceptable performance is possible. Based on this, LC switching appears to be an excellent, low-cost option for DC, as well as RF switching applications.

Author Contributions: M.M conducted the literature search and simulations and wrote the first manuscript draft. F.A. reviewed and edited the manuscript, obtained the permissions for the published data/figures, and drew the schematic diagrams. R.A.C.Jr. proposed and refined the original idea and reviewed the manuscript.

Funding: This research received no external funding.

Acknowledgments: We would like to thank Turja Nandy, Protap K. Mahanta, and Mohammad Shakhawat Hossain for reviewing the final manuscript.

Conflicts of Interest: The authors declare no conflict of interest.

\section{References}

1. Schadt, M. Liquid crystal materials and liquid crystal displays. Annu. Rev. Mater. Res. 1997, 27, 305-379. [CrossRef]

2. Kelly, S.M.; O'Neill, M. Liquid crystals for electro-optic applications. In Handbook of Advanced Electronic and Photonic Materials and Devices; Academic Press: Cambridge, MA, USA, 2001; pp. 1-66. [CrossRef]

3. Dierking, I. Chiral liquid crystals: Structures, phases, effects. Symmetry 2014, 6, 444-472. [CrossRef]

4. Brown, G.H. Structure, properties, and some applications of liquid crystals. JOSA 1973, 63, 1505-1514. [CrossRef]

5. Haas, W.E. Liquid Crystal Display Research: The First Fifteen Years. Mol. Cryst. Liq. Cryst. 1983, 94, 1-31. [CrossRef]

6. Lagerwall, J.P.; Scalia, G. Liquid Crystals with Nano and Microparticles; World Scientific: Singapore, 2017. [CrossRef]

7. Choudhary, A.; Singh, G.; Biradar, A.M. Advances in gold nanoparticle-Liquid crystal composites. Nanoscale 2014, 6, 7743-7756. [CrossRef]

8. Garbovskiy, Y.; Glushchenko, I. Nano-objects and ions in liquid crystals: Ion trapping effect and related phenomena. Crystals 2015, 5, 501-533. [CrossRef]

9. Haraguchi, F.; Inoue, K.I.; Toshima, N.; Kobayashi, S.; Takatoh, K. Reduction of the threshold voltages of nematic liquid crystal electrooptical devices by doping inorganic nanoparticles. Jpn. J. Appl. Phys. 2007, 46, L796. [CrossRef]

10. Khatua, S.; Manna, P.; Chang, W.S.; Tcherniak, A.; Friedlander, E.; Zubarev, E.R.; Link, S. Plasmonic nanoparticles- liquid crystal composites. J. Phys. Chem. C 2009, 114, 7251-7257. [CrossRef] 
11. Sridevi, S.; Prasad, S.K.; Nair, G.G.; D’Britto, V.; Prasad, B.L.V. Enhancement of anisotropic conductivity, elastic, and dielectric constants in a liquid crystal-gold nanorod system. Appl. Phys. Lett. 2010, 97, 151913. [CrossRef]

12. Vardanyan, K.K.; Walton, R.D.; Bubb, D.M. Liquid crystal composites with a high percentage of gold nanoparticles. Liq. Cryst. 2011, 38, 1279-1287. [CrossRef]

13. Reznikov, Y.; Buchnev, O.; Tereshchenko, O.; Reshetnyak, V.; Glushchenko, A.; West, J. Ferroelectric nematic suspension. Appl. Phys. Lett. 2003, 82, 1917-1919. [CrossRef]

14. Lynch, M.D.; Patrick, D.L. Organizing carbon nanotubes with liquid crystals. Nano Lett. 2002, 2, $1197-1201$. [CrossRef]

15. Dierking, I.; Scalia, G.; Morales, P.; LeClere, D. Aligning and reorienting carbon nanotubes with nematic liquid crystals. Adv. Mater. 2004, 16, 865-869. [CrossRef]

16. Lee, W.; Yeh, S.L. Optical amplification in nematics doped with carbon nanotubes. Appl. Phys. Lett. 2001, 79, 4488-4490. [CrossRef]

17. Russell, J.M.; Oh, S.; LaRue, I.; Zhou, O.; Samulski, E.T. Alignment of nematic liquid crystals using carbon nanotube films. Thin Solid Film. 2006, 509, 53-57. [CrossRef]

18. Lagerwall, J.; Scalia, G. Carbon nanotubes in liquid crystals. In Handbook of Liquid Crystals; Wiley: Hoboken, NJ, USA, 2014; pp. 1-40. [CrossRef]

19. Dierking, I.; Scalia, G.; Morales, P. Liquid crystal-Carbon nanotube dispersions. J. Appl. Phys. 2005, 97, 044309. [CrossRef]

20. Jayalakshmi, V.; Prasad, S.K. Understanding the observation of large electrical conductivity in liquid crystal-carbon nanotube composites. Appl. Phys. Lett. 2009, 94, 202106. [CrossRef]

21. Schadt, M. Dielectric properties of some nematic liquid crystals with strong positive dielectric anisotropy. J. Chem. Phys. 1972, 56, 1494-1497. [CrossRef]

22. Schadt, M. Low-frequency dielectric relaxations in nematics and dual-frequency addressing of field effects. Mol. Cryst. Liq. Cryst. 1982, 89, 77-92. [CrossRef]

23. Guralnik, I.R.; Belopukhov, V.N.; Love, G.D.; Naumov, A.F. Interdependence of the electrical and optical properties of liquid crystals for phase modulation applications. J. Appl. Phys. 2000, 87, 4069-4074. [CrossRef]

24. Heilmeier, G.H.; Zanoni, L.A. Guest-host interactions in nematic liquid crystals. A new electro-optic effect. Appl. Phys. Lett. 1968, 13, 91-92. [CrossRef]

25. Thostenson, E.T.; Li, W.Z.; Wang, D.Z.; Ren, Z.F.; Chou, T.W. Carbon nanotube/carbon fiber hybrid multiscale composites. J. Appl. Phys. 2002, 91, 6034-6037. [CrossRef]

26. Baughman, R.H.; Zakhidov, A.A.; De Heer, W.A. Carbon nanotubes-the route toward applications. Science 2002, 297, 787-792. [CrossRef] [PubMed]

27. Tans, S.J.; Verschueren, A.R.; Dekker, C. Room-temperature transistor based on a single carbon nanotube. Nature 1998, 393, 49. [CrossRef]

28. Zhang, J.; Fu, Y.; Wang, C.; Chen, P.C.; Liu, Z.; Wei, W.; Zhou, C. Separated carbon nanotube macroelectronics for active matrix organic light-emitting diode displays. Nano Lett. 2011, 11, 4852-4858. [CrossRef]

29. Munna, M.; Das, P.; Huq, M.F.; Ahmed, I. Study on the On/ Off Ratio of the Cylindrical Surrounding Gate CNT Transistor Using Nonequlibrium Green's Function Approach. J. Sci. Res. 2015, 7, 11-21. [CrossRef]

30. Mahanta, P.K.; Adhikari, P.; Rocky, K.A. Skin effect analysis for carbon nano-material based interconnects at high frequency. In Proceedings of the 2013 2nd International Conference on Informatics, Electronics and Vision (ICIEV), Dhaka, Bangladesh, 17-18 May 2013; pp. 1-6. [CrossRef]

31. Hassan, A.; Nandy, T.; Abedin, M.I.; Islam, M.A.; Dutta, A. Resonant frequency analysis of graphene nanoribbon based VLSI interconnect system. In Proceedings of the 2014 8th International Conference on Informatics, Electronics and Vision (ICIEV), Dhaka, Bangladesh, 20-22 December 2014; pp. 156-159. [CrossRef]

32. Nandy, T.; Coutu, R.; Ababei, C. Carbon Monoxide Sensing Technologies for Next-Generation Cyber-Physical Systems. Sensors 2018, 18, 3443. [CrossRef] [PubMed]

33. Kong, J.; Franklin, N.R.; Zhou, C.; Chapline, M.G.; Peng, S.; Cho, K.; Dai, H. Nanotube molecular wires as chemical sensors. Science 2000, 287, 622-625. [CrossRef] [PubMed]

34. Modi, A.; Koratkar, N.; Lass, E.; Wei, B.; Ajayan, P.M. Miniaturized gas ionization sensors using carbon nanotubes. Nature 2003, 424, 171. [CrossRef] [PubMed]

35. Zakri, C. Carbon nanotubes and liquid crystalline phases. Liq. Cryst. Today 2007, 16, 1-11. [CrossRef] 
36. Chen, H.Y.; Lee, W.; Clark, N.A. Faster electro-optical response characteristics of a carbon-nanotube-nematic suspension. Appl. Phys. Lett. 2007, 90, 033510. [CrossRef]

37. Jeon, S.Y.; Shin, S.H.; Jeong, S.J.; Lee, S.H.; Jeong, S.H.; Lee, Y.H.; Kim, K.J. Effects of carbon nanotubes on electro-optical characteristics of liquid crystal cell driven by in-plane field. Appl. Phys. Lett. 2007, 90, 121901. [CrossRef]

38. Baik, I.S.; Jeon, S.Y.; Jeong, S.J.; Lee, S.H.; An, K.H.; Jeong, S.H.; Lee, Y.H. Local deformation of liquid crystal director induced by translational motion of carbon nanotubes under in-plane field. J. Appl. Phys. 2006, 100, 074306. [CrossRef]

39. Lebovka, N.; Dadakova, T.; Lysetskiy, L.; Melezhyk, O.; Puchkovska, G.; Gavrilko, T.; Baran, J.; Drozd, M. Phase transitions, intermolecular interactions and electrical conductivity behavior in carbon multiwalled nanotubes/nematic liquid crystal composites. J. Mol. Struct. 2008, 887, 135-143. [CrossRef]

40. Ponevchinsky, V.V.; Goncharuk, A.I.; Vasil'ev, V.I.; Lebovka, N.I.; Soskin, M.S. Cluster self-organization of nanotubes in a nematic phase: The percolation behavior and appearance of optical singularities. JETP Lett. 2010, 91, 241-244. [CrossRef]

41. Lisetski, L.N.; Lebovka, N.I.; Sidletskiy, O.T.; Panikarskaya, V.D.; Kasian, N.A.; Kositsyn, S.S.; Melezhyk, O.V. Spectrophotometry and electrical conductivity studies of multiwall nanotubes dispersed in nematic liquid crystals. Funct. Mater. 2007, 14, 233-237.

42. Goncharuk, A.I.; Lebovka, N.I.; Lisetski, L.N.; Minenko, S.S. Aggregation, percolation and phase transitions in nematic liquid crystal EBBA doped with carbon nanotubes. J. Phys. D Appl. Phys. 2009, 42, 165411. [CrossRef]

43. Lebovka, N.I.; Tarafdar, S.; Vygornitskii, N.V. Computer simulation of electrical conductivity of colloidal dispersions during aggregation. Phys. Rev. E 2006, 73, 031402. [CrossRef] [PubMed]

44. Chen, S.H.; Amer, N.M. Observation of macroscopic collective behavior and new texture in magnetically doped liquid crystals. Phys. Rev. Lett. 1983, 51, 2298. [CrossRef]

45. Burylov, S.V.; Raikher, Y.L. On the orientation of an anisometric particle suspended in a bulk uniform nematic. Phys. Lett. A 1990, 149, 279-283. [CrossRef]

46. Burylov, S.V.; Raikher, Y.L. Orientation of a solid particle embedded in a monodomain nematic liquid crystal. Phys. Rev. E 1994, 50, 358. [CrossRef]

47. Polson, J.M.; Burnell, E.E. Monte Carlo simulations of solute ordering in nematic liquid crystals: Shape anisotropy and quadrupole-quadrupole interactions as orienting mechanisms. Phys. Rev. E 1997, 55, 4321. [CrossRef]

48. Harte, A. Liquid crystals allow large-scale alignment of carbon nanotubes. Caltech Undergrad. Res. J. (CURJ) 2001, 1, 44-49. Available online: http://curj.caltech.edu/documents/17-curj_v1n2.pdf (accessed on 25 November 2018).

49. Prasad, S.K.; Sandhya, K.L.; Nair, G.G.; Hiremath, U.S.; Yelamaggad, C.V.; Sampath, S. Electrical conductivity and dielectric constant measurements of liquid crystal-gold nanoparticle composites. Liq. Cryst. 2006, 33, 1121-1125. [CrossRef]

50. Yoshida, H.; Kawamoto, K.; Kubo, H.; Tsuda, T.; Fujii, A.; Kuwabata, S.; Ozaki, M. Nanoparticle-Dispersed Liquid Crystals Fabricated by Sputter Doping. Adv. Mater. 2010, 22, 622-626. [CrossRef] [PubMed]

51. Nishida, N.; Shiraishi, Y.; Kobayashi, S.; Toshima, N. Fabrication of Liquid Crystal Sol Containing Capped Ag- Pd Bimetallic Nanoparticles and Their Electro-Optic Properties. J. Phys. Chem. C 2008, 112, 20284-20290. [CrossRef]

52. Duran, H.; Gazdecki, B.; Yamashita, A.; Kyu, T. Effect of carbon nanotubes on phase transitions of nematic liquid crystals. Liq. Cryst. 2005, 32, 815-821. [CrossRef]

53. Shah, H.J.; Fontecchio, A.K.; Mattia, D.; Gogotsi, Y. Field controlled nematic-to-isotropic phase transition in liquid crystal-carbon nanotube composites. J. Appl. Phys. 2008, 103, 064314. [CrossRef]

54. Baik, I.S.; Jeon, S.Y.; Lee, S.H.; Park, K.A.; Jeong, S.H.; An, K.H.; Lee, Y.H. Electrical-field effect on carbon nanotubes in a twisted nematic liquid crystal cell. Appl. Phys. Lett. 2005, 87, 263110. [CrossRef]

55. Singh-Bhalla, G.; Du, X.; Hebard, A.F. Contribution of interface capacitance to the electric-field breakdown in thin-film Al-AlO x-Al capacitors. Appl. Phys. Lett. 2003, 83, 2417-2419. [CrossRef]

56. Yin, Y.; Shiyanovskii, S.V.; Lavrentovich, O.D. Electric heating effects in nematic liquid crystals. J. Appl. Phys. 2006, 100, 024906. [CrossRef] 
57. Basu, R.; Alfred, G. Insulator-to-conductor transition in liquid crystal-carbon nanotube nanocomposites. J. Appl. Phys. 2016, 120, 164309. [CrossRef]

58. Scalia, G.; Lagerwall, J.P.; Haluska, M.; Dettlaff-Weglikowska, U.; Giesselmann, F.; Roth, S. Effect of phenyl rings in liquid crystal molecules on SWCNTs studied by Raman spectroscopy. Phys. Status Solidi (b) 2006, 243, 3238-3241. [CrossRef]

59. Park, K.A.; Lee, S.M.; Lee, S.H.; Lee, Y.H. Anchoring a liquid crystal molecule on a single-walled carbon nanotube. J. Phys. Chem. C 2007, 111, 1620-1624. [CrossRef]

60. Basu, R. Effects of graphene on electro-optic switching and spontaneous polarization of a ferroelectric liquid crystal. Appl. Phys. Lett. 2014, 105, 112905. [CrossRef]

61. Basu, R.; Garvey, A.; Kinnamon, D. Effects of graphene on electro-optic response and ion-transport in a nematic liquid crystal. J. Appl. Phys. 2015, 117, 074301. [CrossRef]

62. Basu, R.; Kinnamon, D.; Garvey, A. Nano-electromechanical rotation of graphene and giant enhancement in dielectric anisotropy in a liquid crystal. Appl. Phys. Lett 2015, 106, 201909. [CrossRef]

63. Glushchenko, A.; Kresse, H.; Reshetnyak, V.; Reznikov, Y.; Yaroshchuk, O. Memory effect in filled nematic liquid crystals. Liq. Cryst. 1997, 23, 241-246. [CrossRef]

64. Dolgov, L.; Yaroshchuk, O.; Lebovka, M. Effect of electro-optical memory in liquid crystals doped with carbon nanotubes. Mol. Cryst. Liq. Cryst. 2008, 496, 212-229. [CrossRef]

65. Basu, R.; Iannacchione, G.S. Carbon nanotube dispersed liquid crystal: A nano electromechanical system. Appl. Phys. Lett. 2008, 93, 183105. [CrossRef]

66. Kiefer, R.; Weber, B.; Windscheid, F.; Baur, G. In-plane switching of nematic liquid crystals. In Proceedings of the 12th International Display Research Conference (Japan Displays), Hiroshima, Japan, 12-14 Octber 1992; p. 547.

67. Soref, R.A. Field effects in nematic liquid crystals obtained with interdigital electrodes. J. Appl. Phys. 1974, 45, 5466-5468. [CrossRef]

68. Oh-e, M.; Kondo, K. Electro-optical characteristics and switching behavior of the in-plane switching mode. Appl. Phys. Lett. 1995, 67, 3895-3897. [CrossRef]

69. Lee, S.H.; Lee, S.L.; Kim, H.Y. Electro-optic characteristics and switching principle of a nematic liquid crystal cell controlled by fringe-field switching. Appl. Phys. Lett. 1998, 73, 2881-2883. [CrossRef]

70. Volpati, D.; Massey, M.K.; Johnson, D.W.; Kotsialos, A.; Qaiser, F.; Pearson, C.; Coleman, K.S.; Tiburzi, G.; Zeze, D.A.; Petty, M.C. Exploring the alignment of carbon nanotubes dispersed in a liquid crystal matrix using coplanar electrodes. J. Appl. Phys. 2015, 117, 125303. [CrossRef]

71. Basu, R. Effect of carbon nanotubes on the field-induced nematic switching. Appl. Phys. Lett. 2013, 103, 241906. [CrossRef]

72. Lee, W.K.; Choi, Y.S.; Kang, Y.G.; Sung, J.; Seo, D.S.; Park, C. Super-fast switching of twisted nematic liquid crystals on 2D single wall carbon nanotube networks. Adv. Funct. Mater. 2011, 21, 3843-3850. [CrossRef]

73. Liu, Y.; Lim, Y.J.; Kundu, S.; Lee, S.H.; Lee, G.D. Super-fast switching of twisted nematic liquid crystals with a single-wall-carbon-nanotube-doped alignment layer. J. Korean Phys. Soc. 2015, 66, 952-958. [CrossRef]

74. Hsiao, Y.C.; Tang, C.Y.; Lee, W. Fast-switching bistable cholesteric intensity modulator. Opt. Express 2011, 19, 9744-9749. [CrossRef] [PubMed]

75. Yan, J.; Li, Y.; Wu, S.T. High-efficiency and fast-response tunable phase grating using a blue phase liquid crystal. Opt. Lett. 2011, 36, 1404-1406. [CrossRef] [PubMed]

76. Cattaneo, L.; Kouwer, P.H.J.; Rowan, A.E.; Rasing, T. Sub-millisecond nematic liquid crystal switches using patterned command layer. J. Appl. Phys. 2013, 113, 014503. [CrossRef]

77. Xianyu, H.; Gauza, S.; Wu, S.T. Sub-millisecond response phase modulator using a low crossover frequency dual-frequency liquid crystal. Liq. Cryst. 2008, 35, 1409-1413. [CrossRef]

78. Kumar, P.; Kang, S.-W.; Lee, S.H. Advanced bistable cholesteric light shutter with dual frequency nematic liquid crystal. Opt. Mater. Express 2.8 2012, 2, 1121-1134. [CrossRef]

79. Dąbrowski, R.; Celiński, M.; Chojnowska, O.; Kula, P.; Dziaduszek, J.; Urban, S. Compounds with low relaxation frequency and dual frequency mixtures useful for active matrix addressing. Liq. Cryst. 2013, 40, 1339-1353. [CrossRef]

80. Lin, X.W.; Hu, W.; Hu, X.K.; Liang, X.; Chen, Y.; Cui, H.Q.; Lu, Y.Q. Fast response dual-frequency liquid crystal switch with photo-patterned alignments. Opt. Lett. 2012, 37, 3627-3629. [CrossRef] [PubMed] 
81. Mrukiewicz, M.; Perkowski, P.; Garbat, K.; Dabrowski, R. Molecular relaxations in dual-frequency nematic liquid crystals. Liq. Cryst. 2014, 41, 1537-1544. [CrossRef]

82. Xianyu, H.; Wu, S.T.; Lin, C.L. Dual frequency liquid crystals: A review. Liq. Cryst. 2009, 36, 717-726. [CrossRef]

83. Pauluth, D.; Tarumi, K. Advanced liquid crystals for television. J. Mater. Chem. 2004, 14, $1219-1227$. [CrossRef]

84. Prasad, S.K.; Kumar, M.V.; Yelamaggad, C.V. Dual frequency conductivity switching in a carbon nanotube/liquid crystal composite. Carbon 2013, 59, 512-517. [CrossRef]

85. Brust, M.; Kiely, C.J. Some recent advances in nanostructure preparation from gold and silver particles: A short topical review. Colloids Surf. A Physicochem. Eng. Asp. 2002, 202, 175-186. [CrossRef]

86. Jana, N.R.; Gearheart, L.A.; Obare, S.O.; Johnson, C.J.; Edler, K.J.; Mann, S.; Murphy, C.J. Liquid crystalline assemblies of ordered gold nanorods. J. Mater. Chem. 2002, 12, 2909-2912. [CrossRef]

87. Müller, J.; Sönnichsen, C.; Von Poschinger, H.; Von Plessen, G.; Klar, T.A.; Feldmann, J. Electrically controlled light scattering with single metal nanoparticles. Appl. Phys. Lett. 2002, 81, 171-173. [CrossRef]

88. Kossyrev, P.A.; Yin, A.; Cloutier, S.G.; Cardimona, D.A.; Huang, D.; Alsing, P.M.; Xu, J.M. Electric field tuning of plasmonic response of nanodot array in liquid crystal matrix. Nano Lett. 2005, 5, 1978-1981. [CrossRef] [PubMed]

89. Van Delden, R.A.; Van Gelder, M.B.; Huck, N.P.; Feringa, B.L. Controlling the color of cholesteric liquid-crystalline films by photoirradiation of a chiroptical molecular switch used as dopant. Adv. Funct. Mater. 2003, 13, 319-324. [CrossRef]

90. Kumar, S.; Lakshminarayanan, V. Inclusion of gold nanoparticles into a discotic liquid crystalline matrix. Chem. Commun. 2004, 1600-1601. [CrossRef]

91. Kumar, S.; Pal, S.K.; Lakshminarayanan, V. Discotic-decorated gold nanoparticles. Mol. Cryst. Liq. Cryst. 2005, 434, 251-579. [CrossRef]

92. Kumar, S.; Pal, S.K.; Kumar, P.S.; Lakshminarayanan, V. Novel conducting nanocomposites: Synthesis of triphenylene-covered gold nanoparticles and their insertion into a columnar matrix. Soft Matter 2007, 3 , 896-900. [CrossRef]

93. Holt, L.A.; Bushby, R.J.; Evans, S.D.; Burgess, A.; Seeley, G. A 106-fold enhancement in the conductivity of a discotic liquid crystal doped with only 1\% (w/w) gold nanoparticles. J. Appl. Phys. 2008, 103, 063712. [CrossRef]

94. Velev, O.D.; Bhatt, K.H. On-chip micromanipulation and assembly of colloidal particles by electric fields. Soft Matter 2006, 2, 738-750. [CrossRef]

95. Lin, S.; Li, M.; Dujardin, E.; Girard, C.; Mann, S. One-dimensional plasmon coupling by facile self-assembly of gold nanoparticles into branched chain networks. Adv. Mater. 2005, 17, 2553-2559. [CrossRef]

96. Zhang, Y.X.; Zeng, H.C. Template-free parallel one-dimensional assembly of gold nanoparticles. J. Phys. Chem. B 2006, 110, 16812-16815. [CrossRef] [PubMed]

97. Basu, R.; Iannacchione, G.S. Evidence for directed self-assembly of quantum dots in a nematic liquid crystal. Phys. Rev. E 2009, 80, 010701. [CrossRef] [PubMed]

98. Onsager, L. The effects of shape on the interaction of colloidal particles. Ann. N. Y. Acad. Sci. 1949, 51, 627-659. [CrossRef]

99. Hadjichristov, G.B.; Marinov, Y.G.; Petrov, A.G.; Marino, L.; Scaramuzza, N. Dielectric and electrical characterization of 5CB nematic liquid crystal doped with silver nanoparticles. J. Phys. Conf. Ser. 2016, 682, 12015. [CrossRef]

100. Pandey, A.S.; Dhar, R.; Kumar, S.; Dabrowski, R. Enhancement of the display parameters of 4'-pentyl-4-cyanobiphenyl due to the dispersion of functionalized gold nano particles. Liq. Cryst. 2011, 38, 115-120. [CrossRef]

101. Simone, R.; Daniele, L.; Matthias, W.; Ilya, K. Phase change materials. MRS Bull. 2012, 37, 118-123. [CrossRef]

102. Mahanta, P.; Munna, M.; Coutu, R.A., Jr. Performance Comparison of Phase Change Materials and Metal-Insulator Transition Materials for Direct Current and Radio Frequency Switching Applications. Technologies 2018, 6, 48. [CrossRef]

103. Mahanta, P.; Anwar, F.; Coutu, R.A. Novel Test Fixture for Characterizing MEMS Switch Microcontact Reliability and Performance. Sensors 2019, 19, 579. [CrossRef] [PubMed] 
104. Stefanovich, G.; Pergament, A.; Stefanovich, D. Electrical switching and Mott transition in $\mathrm{VO}_{2}$. J. Phys. Condens. Matter 2000, 12, 8837. [CrossRef]

105. Yang, Z.; Changhyun, K.; Shriram, R. Oxide electronics utilizing ultrafast metal-insulator transitions. Annu. Rev. Mater. Res. 2011, 41, 337-367. [CrossRef]

106. Canli, N.Y.; Özdemir, Z.G.; Okutan, M.; Güzeller, D.; Ocak, H.; Eran, B.B. Dielectric Properties of 4-Cyano-4'-pentylbiphenyl (5CB): 4-[4-(S)-2-Methylbutoxybenzoyloxy] benzoic Acid (BAC) Composite. Mol. Cryst. Liq. Cryst. 2015, 623, 17-30. [CrossRef]

107. Garbovskiy, Y.; Zagorodnii, V.; Krivosik, P.; Lovejoy, J.; Camley, R.E.; Celinski, Z.; Dabrowski, R. Liquid crystal phase shifters at millimeter wave frequencies. J. Appl. Phys. 2012, 111, 054504. [CrossRef]

108. Lai, Y.T.; Kuo, J.C.; Yang, Y.J. A novel gas sensor using polymer-dispersed liquid crystal doped with carbon nanotubes. Sens. Actuators A Phys. 2014, 215, 83-88. [CrossRef]

109. Varghese, S.; Narayanankutty, S.; Bastiaansen, C.W.; Crawford, G.P.; Broer, D.J. Patterned Alignment of Liquid Crystals by $\mu$-Rubbing. Adv. Mater. 2004, 16, 1600-1605. [CrossRef]

110. Park, S.; Padeste, C.; Schift, H.; Gobrecht, J.; Scharf, T. Chemical nanopatterns via nanoimprint lithography for simultaneous control over azimuthal and polar alignment of liquid crystals. Adv. Mater. 2005, 17, 1398-1401. [CrossRef]

111. Chiu, C.H.; Kuo, H.L.; Chen, P.C.; Wen, C.H.; Liu, Y.C.; Chen, H.M.P. Nanoimprinting-lithography-induced self-aligned liquid crystals for novel multifunctional optical films. Appl. Phys. Lett. 2006, 88, 073509. [CrossRef]

112. Lin, T.C.; Yu, S.C.; Chen, P.S.; Chi, K.Y.; Pan, H.C.; Chao, C.Y. Fabrication of alignment layer free flexible liquid crystal cells using thermal nanoimprint lithography. Curr. Appl. Phys. 2009, 9, 610-612. [CrossRef]

113. Kim, J.H.; Yoneya, M.; Yokoyama, H. Tristable nematic liquid-crystal device using micropatterned surface alignment. Nature 2002, 420, 159. [CrossRef] [PubMed]

114. Pavlov, I.; Rybak, A.; Dobrovolskiy, A.; Kadan, V.; Blonskiy, I.; Ilday, F.Ö.; Gvozdovskyy, I. The alignment of nematic liquid crystal by the Ti layer processed by nonlinear laser lithography. Liq. Cryst. 2018, 45, 1265-1271. [CrossRef]

115. Premkumar, T.; Mezzenga, R.; Geckeler, K.E. Carbon nanotubes in the liquid phase: Addressing the issue of dispersion. Small 2012, 8, 1299-1313. [CrossRef]

116. Schymura, S.; Kühnast, M.; Lutz, V.; Jagiella, S.; Dettlaff-Weglikowska, U.; Roth, S.; Frank, G.; Carsten, T.; Giusy, S.; Lagerwall, J. Towards efficient dispersion of carbon nanotubes in thermotropic liquid crystals. Adv. Funct. Mater. 2010, 20, 3350-3357. [CrossRef] 